\title{
Avaliação ponderada sobre a percepção da infraestrutura de calçadas por meio da técnica Delphi-Fuzzy e análises geoespaciais
}

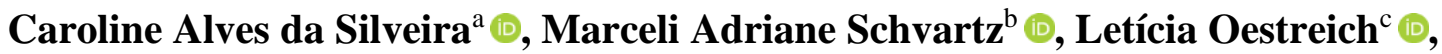 Carmen Brum Rosa ${ }^{\mathrm{d}}$, Bárbara Giaccom ${ }^{\mathrm{e}}$ \\ e Alejandro Ruiz-Padillo ${ }^{\mathrm{f}}$}

${ }^{a}$ Universidade Federal de Santa Maria, Campus Cachoeira do Sul, Laboratório de Mobilidade e Logística, Cachoeira do Sul, RS, Brasil. E-mail: caroline.alves.silveira@gmail.com

${ }^{\mathrm{b}}$ Universidade Federal de Santa Maria, Campus Cachoeira do Sul, Laboratório de Mobilidade e Logística, Cachoeira do Sul, RS, Brasil. E-mail: schvartz.marceli@gmail.com

\footnotetext{
${ }^{\mathrm{c}}$ Universidade Federal de Santa Maria, Programa de Pós-Graduação em Engenharia de Produção, Laboratório de Mobilidade e Logística, Santa Maria, RS, Brasil. E-mail: leticia.oestreich@ @otmail.com

${ }^{d}$ Universidade Federal de Santa Maria, Departamento de Engenharia de Produção e Sistemas, Laboratório de Mobilidade e Logística, Santa Maria, RS, Brasil. E-mail: carmen.b.rosa@ufsm.br

e Universidade Federal de Santa Maria, Campus Cachoeira do Sul, Laboratório de Mobilidade e Logística, Cachoeira do Sul, RS, Brasil. E-mail: barbara.giaccom@ufsm.br

${ }^{\mathrm{f}}$ Universidade Federal de Santa Maria, Departamento de Transportes, Laboratório de Mobilidade e Logística, Santa Maria, RS, Brasil. E-mail: alejandro.ruiz-padillo@ufsm.br
}

Submetido em 05 de janeiro de 2021. Aceito em 15 de junho de 2021. https://doi.org/10.47235/rmu.v9i2.186

\begin{abstract}
Resumo. Para promover a caminhada nas cidades é necessário prover condições adequadas de infraestrutura relacionadas às calçadas. No entanto, são inúmeras as variáveis que podem interferir na percepção da qualidade das calçadas por parte dos usuários dessas vias. Dessa forma, esse estudo se propõe a apresentar um método de avaliação da qualidade das calçadas utilizando um índice ponderado com base em análises geoespaciais e na percepção dos usuários. As análises quantitativas realizadas envolvem a aplicação da lógica fuzzy, e as técnicas Delphi e Schulze. O método foi aplicado na área central de uma cidade brasileira de pequeno porte localizada no estado do Rio Grande do Sul. Os resultados do estudo são discutidos com base na seleção dos atributos importantes para a caminhada e ponderação e percepção desses atributos. De uma maneira geral, a análise de sensibilidade mostra que o método é adequado e que, portanto, consegue transmitir diretamente as experiências vivenciadas no ambiente urbano. Assim, este estudo contribui com a proposição de um método que pode ser utilizado por planejadores urbanos para tomar decisões relacionadas a políticas públicas voltadas a mobilidade de pedestres.
\end{abstract}

Palavras-chave: percepção, infraestrutura urbana, SIG, delphi, fuzzy. 


\section{Introdução}

Andar é o principal e mais antigo meio de deslocamento e possui diversos benefícios relacionados à saúde, no entanto, a promoção de mobilidade urbana sustentável e inclusiva, apresenta aos planejadores o desafio de implementar espaços acessíveis e seguros (Woldeamanuel e Kent, 2016). Além disso, promover o transporte ativo pode reduzir significativamente os custos de congestionamento, manutenção de estradas, estacionamento e acidentes com veículos automotores (Litman, 2021).

Elementos da morfologia urbana são capazes de possibilitar a conexão visual e funcional entre os espaços, e a formação de uma imagem ambiental coerente dos distintos setores urbanos. A estrutura estabelece a coerência das relações entre as imagens ambientais, que é determinada pela permeabilidade ou acessibilidade funcional, característica crítica para a qualidade do espaço aberto (Francis, 1987), além da permeabilidade de um sistema de espaços e a legibilidade da estrutura, que são características definidoras da qualidade visual da imagem urbana.

Morfologicamente, a análise da configuração do espaço baseia-se nas relações das partes (do sistema, espaço ou edificação) por meio de suas conexões. Neste sentido, as barreiras e as conexões físicas entre os espaços interferem no modo como os indivíduos se comportam e relacionam, bem como no modo como as atividades se desenvolvem. Estudos têm demonstrado a importância da sintaxe espacial para modelar e entender os padrões e estruturas urbanos (e.g., Jiang e Claramunt, 2002; Faria, 2010). Segundo a teoria do movimento natural (Hillier et al., 1993), a distribuição do movimento acontece em função da configuração espacial. Os padrões ou estruturas espaciais exercem um grande impacto sobre as atividades e comportamentos humanos nos espaços urbanos. Seguindo esta linha de análise, os padrões e potenciais de movimento (de pessoas, veículos, informações etc.) no espaço urbano têm sido investigados e modelados, possibilitando análises dos usos dos espaços, orientação espacial, acessibilidade, centralidade, integração local e global (Jiang e Claramunt, 2002; Hillier, 1996).
As cidades funcionam em virtude da mobilidade e do intercâmbio. A sintaxe espacial (Hillier e Hanson, 1984) aponta, de uma forma geral, quais espaços ou vias mais integradas permitem acesso mais fácil a partir dos demais espaços ou vias do sistema, enquanto que a menor integração é associada à segregação ou isolamento em relação ao conjunto de espaços do sistema. A continuidade é importante para o espaço público, para os sistemas de mobilidade e para os espaços verdes (Medeiros, 2006).

Associado à morfologia urbana, proporcionar condições de conforto aos pedestres durante $o$ planejamento viário, a fim de estimular a prática de caminhada, é de grande importância (Bivina et al., 2018; Moran et al., 2020), uma vez que a percepção do indivíduo sobre o ambiente influencia na sua escolha para realizar os seus deslocamentos. Nesse sentido, surge o conceito de caminhabilidade, que de maneira simplificada, representa a qualidade de um espaço para caminhadas (Pitilin e Sanches, 2020) e possibilita motivar as pessoas a adotarem viagens a pé como forma de deslocamento (Ghidini, 2011). A caminhabilidade (do inglês, walkability) mensura a capacidade de caminhar em um ambiente, e contribui tanto com a vitalidade urbana, como também atua como um indicador desta vitalidade (Speck, 2012). Do mesmo modo, a presença de comércios e serviços constitui um importante atributo para o estímulo à caminhada, como é o caso dos centros urbanos que possuem o uso do solo mais diversificado, também muitas vezes relacionado com melhores condições da infraestrutura de calçadas (Oestreich et al., 2018).

Alguns autores asseguram que as pessoas realizam seus deslocamentos a pé preferencialmente em locais que possuem características como: condições adequadas do desenho urbano (Ewing e Cervero, 2001), vias conectadas, com a presença de comércios e serviços (Liao et al., 2018) e calçadas largas, com pavimento em boas condições (Lee, Abdel-Aty e Shah, 2019), em um ambiente seguro (Li et al., 2020). Percebe-se uma diversidade de elementos que impulsionam a caminhada e que estão ligados ao ambiente, à percepção e ao comportamento dos usuários (Guimarães Silva, 2019; Silva Júnior, Kikuchi e Portella, 2020). Para Gehl (2013) e Speck (2012) há muito mais em caminhar do que simplesmente "an- 
dar", a prática envolve a troca de experiências entre as pessoas e a comunidade do entorno, bem como com os espaços (livres ou edificados) e o mobiliário urbano ao nível dos olhos.

No Brasil, $36 \%$ dos brasileiros utilizam como principal meio de transporte seus próprios pés (ANTP, 2017), e nos municípios de menor porte, a participação dos transportes de modos ativos é ainda mais elevada (ANTP, 2016). Porém, a infraestrutura destinada à mobilidade para pedestres apresenta piores condições nas cidades de pequeno porte (Doescher et al., 2014). A definição de um instrumento para avaliar o nível de serviço oferecido por esses espaços é uma das principais dificuldades dos gestores em relação à qualidade dos espaços urbanos (Ferreira e Sanches, 2001; Golan et al., 2019; ITDP, 2019). Dessa forma, analisar os fatores que influenciam e estimulam a caminhada, levando em conta as percepções da população sobre a qualidade da infraestrutura das calçadas, pode auxiliar na formulação de medidas para planejamento de cidades. Além disso, abordagens anteriores sobre o tema não alcançaram consensos entre diferentes grupos populacionais nem levaram em conta a incerteza intrínseca que possuem as percepções subjetivas dos usuários dos espaços públicos e da infraestrutura de mobilidade urbana sobre esses aspectos do ambiente construído.

Com base nisso, o objetivo deste estudo é propor um método de avaliação sobre a qualidade da infraestrutura das calçadas mediante um índice ponderado a partir da análise geoespacial da percepção de usuários e de responsáveis pelos estabelecimentos comerciais e de serviços. O estudo foi aplicado ao longo da área central de Cachoeira do Sul, uma cidade de pequeno porte do interior do Rio Grande do Sul (Brasil). O método identifica quais as características e atributos da infraestrutura das calçadas podem influenciar na escolha pelo modo de transporte a pé, agregando as importâncias relativas e percepções sobre os atributos envolvidos. O estudo contribui como uma ferramenta de análise para tomada de decisões para gestores públicos, como parte de uma busca por melhorias na infraestrutura dos passeios públicos de forma mais eficiente $\mathrm{e}$ justificada.

\section{Metodologia}

As etapas definidas para alcançar o objetivo proposto no estudo foram divididas em três fases, conforme o procedimento metodológico esquematizado na Figura 1.

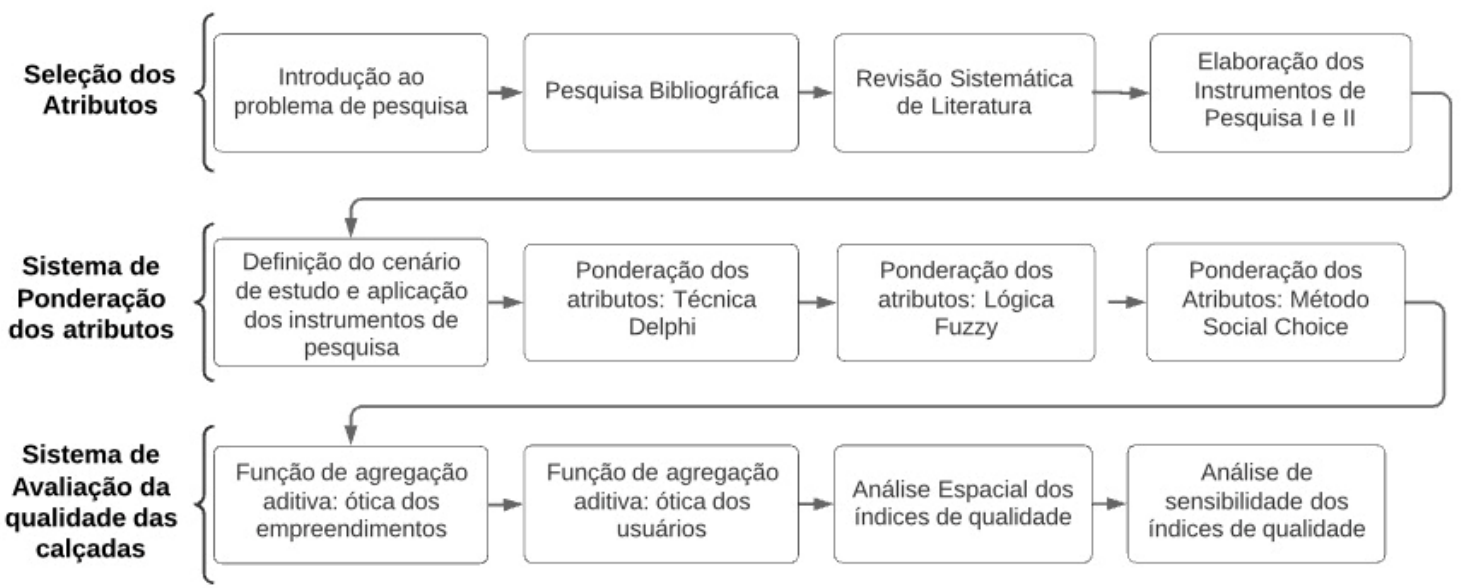

Figura 1. Procedimento metodológico (fonte: elaborada pelos autores).

O cumprimento da primeira fase, referente à identificação e à seleção dos atributos que compõem o modelo matemático para geração do índice de qualidade das calçadas, deu-se a partir de uma revisão sistemática da literatura (RSL) norteada pela resposta ao problema de pesquisa. Posto isso, fez-se a estruturação dos instrumentos de pesquisa I e II, que questionaram aos responsáveis dos empreendimentos comerciais e aos usuários acerca do grau de importância de cada atributo e de seu desempenho no espaço delimitado.

A aplicação dos instrumentos I e II deu-se com a definição do cenário de estudo: a região central da cidade de Cachoeira do Sul, localizada no centro do estado do Rio Grande do Sul e classificada como uma cidade de pequeno porte (ANTP, 2017). A Figura 2 evidencia a grande concentração de estabelecimentos 
comerciais em suas quatro principais vias (i.e., ruas $\mathrm{A}, \mathrm{B}, \mathrm{C}$ e E).

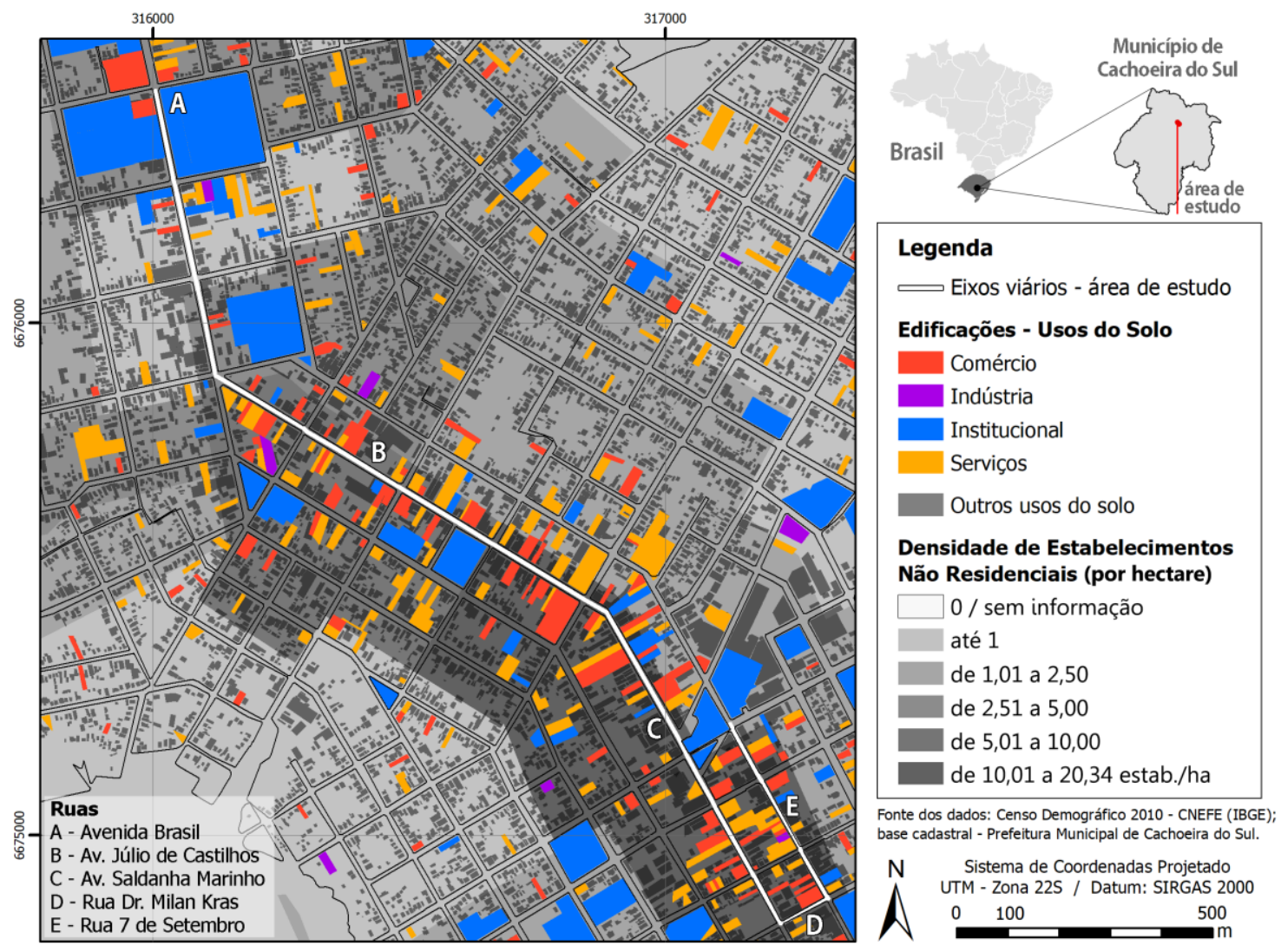

Figura 2. Localização das ruas que compõem a área de estudo (fonte: elaborada pelos autores).

A partir da coleta de dados, operacionalizouse o sistema de ponderação dos atributos. A utilização de uma metodologia híbrida associando a técnica Delphi, a lógica fuzzy e o método Schulze (função de escolha social ou Social Choice Function - SCF), descritas nas subseções seguintes, permitiu a quantificação da importância de cada atributo.

A fase final da pesquisa compreende a geração do índice de qualidade das calçadas baseado em um sistema de avaliação. A função de agregação aditiva permitiu a verificação da condição da calçada em cada atributo e o resultado do modelo indica a condição dos pontos que compõem o cenário de pesquisa sob o objetivo central de mensurar o nível de qualidade das calçadas. A partir do índice gerado, analisaram-se espacialmente os desempenhos e discutiram-se os resultados. Somado a isso, fez-se a análise de sensibilidade para determinar o efeito da variação de importância nos atributos considerados pelos estabelecimentos e pelos usuários no índice final de qualidade das calçadas.

\section{Revisão Sistemática de Literatura (RSL)}

A RSL consiste no emprego de métodos explícitos e ordenados para identificação, seleção e avaliação criteriosa de estudos (Rother, 2007) e, neste trabalho, foi conduzida com o objetivo de fundamentar teoricamente os conceitos envolvidos e mais citados em pesquisas de caminhabilidade e infraestrutura de calçadas. Por meio da plataforma Web of Science, buscaram-se publicações consideradas atuais, no período de 2010 a 2020, através das palavras-chave walkability e sidewalks (i.e., caminhabilidade e calçadas, respectivamente). A partir delas, foram selecionados documentos "Artigos" nas categorias da pesquisa Urban Morphology, Transportation e Transportation Science Technology (i.e., Morfologia Urbana, Transportes e Tecnologia da Ciência dos Transportes, respectivamente). Por questões de espaço, esse processo de investigação sistemática não será relatado detalhadamente neste artigo.

\section{Técnica Delphi}

Tendo em vista que a importância relativa dos 
critérios, identificados pela RSL, devem ir ao encontro da necessidade comum do cenário de pesquisa segundo a percepção dos responsáveis dos estabelecimentos comerciais e de serviços, utilizou-se a técnica Delphi, que combina abordagens qualitativas e quantitativas para alcançar um acordo formal. A técnica Delphi foi desenvolvida para obter o consenso de opinião mais confiável em um grupo de especialistas por meio de uma série de questionários intensivos intercalados com um feedback controlado destas opiniões (Linstone e Turoff, 2002).

Nos últimos anos, a técnica Delphi provou ser um instrumento de pesquisa válido, especialmente quando se tem o objetivo de prospecção sobre algum tema. Desde então, a técnica tem sido vista como uma das ferramentas mais utilizadas em previsões e como suporte à tomada de decisões, além de ser empregada como um mecanismo eficiente para discussão em grupo estruturado com foco na resolução de problemas futuros (Spickermann, Zimmermann e Von Der Gracht, 2014). Nesse contexto, a metodologia Delphi é uma abordagem adequada para analisar as opiniões dos um subgrupo de uma população para alcançar uma compreensão dos desenvolvimentos futuros e incertos para identificar problemas, soluções e desafios que são economicamente relevantes (Konu, 2015) além de integrar, coletar e agregar opiniões e julgamentos em um contexto de decisão coletiva.

Nesse trabalho, a técnica Delphi foi adaptada para captar as percepções dos responsáveis dos estabelecimentos comerciais do cenário de estudo acerca dos atributos selecionados na RSL sobre infraestrutura das calçadas. Para tanto, foi elaborado o instrumento de pesquisa I, no formato de um questionário semiaberto contendo questões fechadas, para determinar o grau de importância de cada atributo de maneira geral sobre a infraestrutura das calçadas, e um questionamento aberto para indicação de outros atributos não listados. $\mathrm{O}$ julgamento dos atributos por meio da determinação do grau de importância foi estabelecido pelo respondente através de uma escala Likert de nove pontos.

O processo de implementação da técnica Delphi se dá em várias etapas, que, segundo Linstone e Turoff (2002), podem ser divididas em: (1) Escolha do grupo de participantes da pesquisa; (2) Construção do questionário; (3)
Primeiro contato com os participantes e convite para participação na pesquisa; (4) Aplicação do questionário; (5) Recebimento das respostas ao questionário; (5) Análise qualitativa e quantitativa das respostas; (6) Construção e envio do questionário com feedback; (7) Recebimento das novas respostas ao questionário e sua análise; (8) Envio das seguintes rodadas de questionários, intercalando com as respetivas análises; e (9) Final do processo e escrita do relatório final.

O uso mais comum da técnica Delphi, no entanto, tem sido através da elaboração de um instrumento de pesquisa pelo pesquisador contendo um conjunto de indicadores que julga serem fundamentais para determinada avaliação. $\mathrm{O}$ demandante pede a colaboração para leitura crítica, dando aos colaboradores um prazo para correção, acréscimos e supressões (Magnier-Watanabe e Lemaire, 2018). Ao receber as respostas, cabe ao pesquisador ou ao grupo de investigação a incorporação das sugestões e a síntese das contribuições. Essa técnica tem um valor fundamental para validação tanto de instrumentos como de resultados de investigação.

De posse desses argumentos, o método de trabalho abordado neste estudo foi a aplicação do instrumento seguindo as etapas que emergem da utilização do Delphi a fim da coleta de percepção de importância de cada atributo.

Posto isso, na seção seguinte é apresentada e discutida a lógica utilizada para as métricas de ponderação dos atributos. Ao mesmo tempo, mediante o instrumento de pesquisa II, os responsáveis dos estabelecimentos comerciais indicaram sua percepção sobre a qualidade específica do trecho de calçada na frente do seu empreendimento segundo cada um dos atributos, com apoio de uma escala Likert de 5 pontos.

\section{Lógica fuzzy}

O processo de avaliação de importância resultante da percepção de respondentes é geralmente impreciso e contém muitas incertezas, em virtude, principalmente, do caráter subjetivo das opiniões. Nesse sentido, considera-se relevante a aplicação da lógica fuzzy no tratamento dos dados. A lógica fuzzy é uma teoria matemática que leva em consideração o aspecto da incerteza na análise de problemas do cotidiano (Saraiva, 2000; Ruiz-Padillo et al., 2018), manipulando informações qualita- 
tivas de forma rigorosa, considerando o modo como a falta de exatidão e a incerteza são descritas.

Desta forma, a lógica fuzzy vem sendo empregada para a solução de problemas reais, principalmente na análise de problemas onde a tomada de decisões desempenha um papel importante (Saraiva, 2000). O grande diferencial da lógica fuzzy se dá no tratamento da teoria dos conjuntos com a relativização entre valores por meio do grau de pertinência de um elemento a um universo, sendo que a pertinência é retratada por uma função que assume valores que indicam o grau de atribuição de um elemento a um dado conjunto (Krykhtine,

$$
O_{i}=\left(L_{i}, M_{i}, U_{i}\right)=\left(\sqrt[k]{\prod_{j} l_{i j}}, \sqrt[k]{\prod_{j} m_{i j}}, \sqrt[k]{\prod_{j} u_{i j}}\right)
$$

Assim, os respondentes forneceram um julgamento sobre o grau de importância de cada atributo que foi tratado matematicamente a partir da equivalência com uma escala linguística difusa, conforme estabelece a lógica fuzzy. As respostas enquadradas fora do consenso foram retornadas aos respondentes para que fossem respondidas novamente sob a ótica dos resultados das rodadas anteriores da técnica Delphi. Isto é, a média geométrica das respostas de todos os respondentes da aplicação do instrumento de pesquisa I orientou a seguinte rodada em busca do consenso de opiniões, caracterizando assim o método Delphi-Fuzzy.

No término da última rodada de aplicação do instrumento I, uma vez que os resultados de consenso foram alcançados, os pesquisadores analisaram os dados, e os números fuzzy triangulares de cada um dos atributos de avaliação foram defuzzificados por meio da técnica do Centro da Área (CA) (Hsieh, Lu e Tzeng, 2004). O valor numérico associado a cada atributo, correspondente ao respectivo grau de importância do atributo i, definido pelo valor de $G_{i}$, é obtido pela Equação 2:

$$
G_{i}=\frac{\left(U_{i}-L_{i}\right)+\left(M_{i}-L_{i}\right)}{3}+L_{i}
$$

Os resultados de importância dos atributos foram posteriormente normalizados em uma escala percentual.

\section{Método Schulze (SCF)}

A importância dos atributos pode ser vista como uma ordenação de variáveis conforme a escolha feita pela população de interesse do
2013).

O tratamento dos dados foi iniciado pela organização das opiniões dos respondentes e determinação dos números fuzzy triangulares para cada um dos atributos apresentados no instrumento de pesquisa I, procedentes da RSL. Assim, tem-se um número fuzzy $o_{i j}=$ $\left(l_{i j}, m_{i j}, n_{i j}\right)$ para cada atributo i e cada respondente j. O valor final para cada atributo $O_{i}$ foi obtido a partir da média geométrica das avaliações de todos os especialistas, que, de acordo com os princípios matemáticos da lógica fuzzy, é calculada a partir da Equação 1 :

estudo. Nesse sentido, as SCF são técnicas que permitem avaliar a escolha de candidatos (atributos) dentro de um conjunto de outros concorrentes expressando as preferências dos entrevistados. Essas funções são comumente utilizadas em eleições políticas, onde se pretende eleger um candidato com base no número de votos recebidos por eles. No entanto, vêm sendo amplamente utilizadas para a tomada de decisão em estudos que envolvem análises multicritério e modelos matemáticos e computacionais (Ruiz-Padillo et al., 2016; Csar, Lackner e Pichler, 2018).

Dentre as diferentes SCF existentes, o presente estudo utilizou a caracterizada pelo método Schulze, ou também beatpath method, que é um dos métodos recentes mais disseminados (Schulze, 2011; Ruiz-Padillo et al., 2016; Csar, Lackner e Pichler, 2018) para avaliar a percepção de importância de atributos desde o ponto de vista dos usuários da infraestrutura (pedestres) e confrontar com as percepções captadas dos responsáveis dos estabelecimentos. Para isso, foram realizadas entrevistas presenciais com residentes do bairro centro da cidade, onde se localiza o cenário de estudo, aos que se solicitou que ordenassem por importância os atributos apresentados, de acordo com o ponto de vista desses usuários sobre a qualidade da infraestrutura das calçadas. No total, foram realizadas 35 entrevistas, baseadas em uma amostra representativa da população do bairro, conforme informações de gênero e idade obtidas pelo IBGE (2012). 
O método Schulze consiste em uma comparação entre pares onde utiliza-se o conceito de "derrota transitiva", considerando as vitórias intermediárias entre o comparativo de preferências dos candidatos (Schulze, 2011). Esse procedimento é aplicado utilizando-se de uma matriz de preferências (de tamanho $n \times n$ ), onde $\mathrm{n}$ é o número de atributos comparáveis. A matriz representa o número absoluto de vitórias de um atributo em comparação aos demais a partir das classificações dos respondentes, que, dessa forma, obtém "votos". Comparando o número de votos total de cada atributo, cada elemento da matriz $e_{i j}$ pode receber os seguintes valores: 1 , se $o$ atributo i tiver sido classificado em uma posição mais alta que $\mathrm{o}$ atributo $\mathrm{j}$ no número absoluto de votos; -1, caso contrário; e 0 , se houver empate entre os atributos comparados (RuizPadillo et al., 2016). O resultado do algoritmo oferece um ranqueamento dos atributos e, ainda, valores de pesos a partir do número de vitórias obtidas em cada comparação.

\section{Análise espacial: Sistema de Informação Ge- ográfica}

Os Sistemas de Informação Geográfica (SIG) permitem a manipulação de dados por meio de pesquisas e combinações variadas, auxiliadas por representação gráfica, vetorial ou matricial. Nos SIGs, ferramentas importantes para tomada de decisões, a base de dados digital é georreferenciada. Toda manipulação ou análise de tais geodados é desempenhada por meio do geoprocessamento, que corresponde à área do conhecimento que utiliza técnicas matemáticas e computacionais para o tratamento da informação geográfica (Câmara, Davis e Monteiro, 2001).

Análise espacial é composta por um conjunto de procedimentos encadeados cuja finalidade é a escolha de um modelo inferencial que considere explicitamente o relacionamento espacial presente no fenômeno (Câmara, Davis e Monteiro, 2001). Igualmente, permite realizar uma ligação entre a propriedade cartográfica e as áreas de análise, estatística e modelagem e, a partir delas, criar e analisar novas variáveis (Rosa, 2011).

A principal proposta neste trabalho é a oportunidade dos gestores públicos de avaliarem a qualidade da infraestrutura das calçadas e, assim, identificar os locais que precisam de intervenções, bem como quais os tipos de intervenção necessários para a melhoria. Dessa maneira, os dados coletados pela aplicação dos instrumentos de pesquisa I e II foram georreferenciados com base na localização do estabelecimento comercial do respondente, o que permitiu observar a distribuição espacial dos valores de importância dos atributos, assim como incorporar a informação da sua localização geográfica às percepções da qualidade dos trechos de calçadas na frente do seu empreendimento, bem como relacioná-los com os elementos do ambiente construído.

Além do uso desagregado dos dados, espacializados em localizações pontuais referentes aos respondentes, também foi realizada a integração dos dados em trechos de via (espaço geográfico contido entre duas esquinas) (Batty, 2004), neste caso, considerando cada uma das calçadas (dois trechos por via), ou seja, em vez de se manipular diversos dados pontuais contidos no espaço geográfico de um trecho de calçada, adotou-se um valor único, de cada variável do estudo, para cada trecho de calçada analisado. Este modo de representação espacial baseia-se na ideia da conectividade entre espaços. Para isto, calculou-se a média dos valores das variáveis observadas (importância e qualidade dos atributos das calçadas). Esta suavização dos dados pretendeu obter um valor médio para um espaço (trecho de calçada). Embora as características físicas não sejam sempre uniformes ao longo de todo trecho de calçada, esta agregação se fez necessária para poder caracterizar uma unidade de ação de medidas de fiscalização e melhoria da infraestrutura. É importante ressaltar que dificuldades pontuais podem ser críticas de acordo com limitações de locomoção do pedestre, como declividades excessivas, degraus e desníveis, buracos e saliências, entre outros.

\section{Resultados e discussões}

\section{Seleção dos Atributos}

Grande parte dos artigos consultados através de uma revisão sistemática de literatura nas áreas Morfologia Urbana, Transportes e Tecnologia da Ciência dos Transportes propõem métodos para determinação do índice de caminhabilidade ou avaliação da qualidade de espaços para pedestres, o que deixa claro que há uma grande quantidade e diversidade de fatores influentes nesse meio e que possuem 
diferente importância e forma de avaliação. Dentre os atributos levantados, destacam-se a atratividade visual, através de aspectos estéticos como arborização, mobiliário urbano, vitrines etc., a presença de comércios e serviços no entorno e a conectividade das vias como fatores mais estimulantes à caminhada (Schreuer et al., 2019; D’Orso e Migliore, 2020; Liu et al., 2020). Além disso, a percepção de segurança pública, por meio da presença e patrulhamento de policiais e de índices de criminalidade, bem como a segurança viária, são aspectos também relevantes (Battista e Manaugh, 2019; Yencha, 2019).

No âmbito dos atributos propriamente de infraestrutura, destacam-se a acessibilidade universal, que, por meio de elementos como rampas, piso tátil, painéis informativos em braile etc., inclui pessoas com as mais diversas características antropométricas e sensoriais, como pessoas com restrição de mobilidade (Bentzen et al., 2020; Pembuain, Priyanto e Suparma, 2020); a drenagem, para garantir ao usuário, por meio de medidas que auxiliem o escoamento de águas pluviais, que não haja acúmulo de água na superfície do passeio e, assim, não comprometa a segurança do pedestre em um possível desvio de sua rota pelo leito dos carros (Hermida, Cordero e Orellana, 2019); e a iluminação, que deve garantir condições mínimas para o tráfego de pedestres quando não há luz natural nas calçadas, nas faixas de travessia, interseções, passarelas e outros trechos de rota de pedestres (Lamour, Morelli e Marins, 2019; Rišová e Madajová, 2020).

Os obstáculos permanentes, como postes de iluminação pública e de fornecimento de energia elétrica, árvores plantadas no meio da calçada, bancas de jornal, abrigos de pontos de ônibus, placas de sinalização, e os obstáculos temporários, como carros estacionados na calçada, mesas e cadeiras de bares ou restaurantes, são elementos que podem bloquear os deslocamentos dos usuários e interferir no trajeto (Bivina et al., 2018; Chan, 2019; ITDP, 2019; Schwanen e Banister, 2019; HerrmannLunecke, Mora e Sagaris, 2020). Já a sinalização, seja ela horizontal, vertical ou através de dispositivos auxiliares, tem a função de orientar e prover informações sobre o ambiente e o sistema viário na escala do pedestre (Battista e Manaugh, 2019).
Sobre a escolha do material que reveste a superfície, ressalta-se que esta submete-se à influência de diversos fatores, como condições climáticas, fluxo de pedestres, topografia, tipo de subsolo, periodicidade de manutenção, uso e ocupação do solo, e carga a qual o piso será (Trubina, 2020). Além disso, deve garantir qualidade, durabilidade, conforto de rolamento, características antiderrapantes e facilidade de manutenção e reposição (Hallal, Reis e Parra, 2010).

Destacam-se também a condição da superfície, que engloba a firmeza e continuidade do pavimento, bem como a presença de buracos e fissuras (ITDP, 2019; Lamour, Morelli e Marins, 2019; Su et al., 2019); a declividade, considerando não somente a topografia local, mas também a quantidade de subidas, descidas e degraus em um trecho, seja transversal ou longitudinalmente (Aghaabbasi et al., 2017; Orellana et al., 2020) e, por fim, a largura da calçada, referente ao espaço disponível para o trânsito dos pedestres (RodriguezValencia et al., 2020; Wu, Chen e Liao, 2019). Tais fatores permitem identificar o grau de conforto para os usuários realizarem seus deslocamentos, bem como relacionar o alinhamento do espaço disponível à demanda.

Os aspectos físicos precisam ser considerados observando-se a condição local da calçada, ponto a ponto. Por exemplo, quando se fala em declividade da calçada é importante dissociar tal característica da topografia local e da declividade do sistema viário, pois intervenções pontuais nas calçadas, como rampas para acesso de veículos a lotes, produzem declividades diferentes nas calçadas em comparação com a inclinação da via destinada ao deslocamento de veículos. Desta forma, a acessibilidade local para todos os pedestres fica sujeita às diferenças nas calçadas produzidas pelo proprietário do lote, que, não raramente, objetiva facilitar a entrada em seu imóvel e não a circulação dos pedestres ao longo da calçada.

Portanto, a existência de calçada é tida como um dos fatores mais importantes para a caminhada, e a deficiência de infraestrutura das calçadas ou, até mesmo, a falta, provoca descontinuidades no passeio, sendo um atributo essencial para a garantia da segurança viária dos pedestres (Bivina et al., 2018; Larrañaga et al., 2019). Ressalta-se, ao mesmo tempo, que são vários os atributos que influenciam na 
qualidade da infraestrutura da calçada e na sua percepção pelos usuários, com diferentes graus de importância. Dentre eles, destacamse as condições da superfície como o atributo com maior peso relativo para os usuários, como no estudo de Bivina et al. (2018), mas também a declividade é vista como uma das principais barreiras para a mobilidade ativa, uma vez que exige mais esforço físico dos pedestres (Larrañaga et al., 2019). Igualmente, a largura da calçada pode ser vista como um atributo que reforça as questões de segurança (Bivina et al., 2018; ITDP, 2019) e melhora as condições de conforto da caminhada, na garantia de mais espaço onde os pedestres trafegam (Marisamynathan e Lakshmi, 2018).

\section{Ponderação e avaliação dos Atributos}

O processo de ponderação e avaliação dos atributos teve início com a análise da aplicação do instrumento de pesquisa I e II, para captação das percepções dos responsáveis dos comércios e serviços sobre grau de importância e qualidade em relação aos 10 atributos principais sobre infraestrutura de calçadas reportados na literatura. Para tanto, contabilizou-se o número total de estabelecimentos endereçados no cenário de estudo. Foram identificados 310 estabelecimentos, dos quais foi definida como amostra representativa, com $99 \%$ de nível de confiança e 5\% de margem de erro, um total de 212 estabelecimentos nos trechos sob análise.

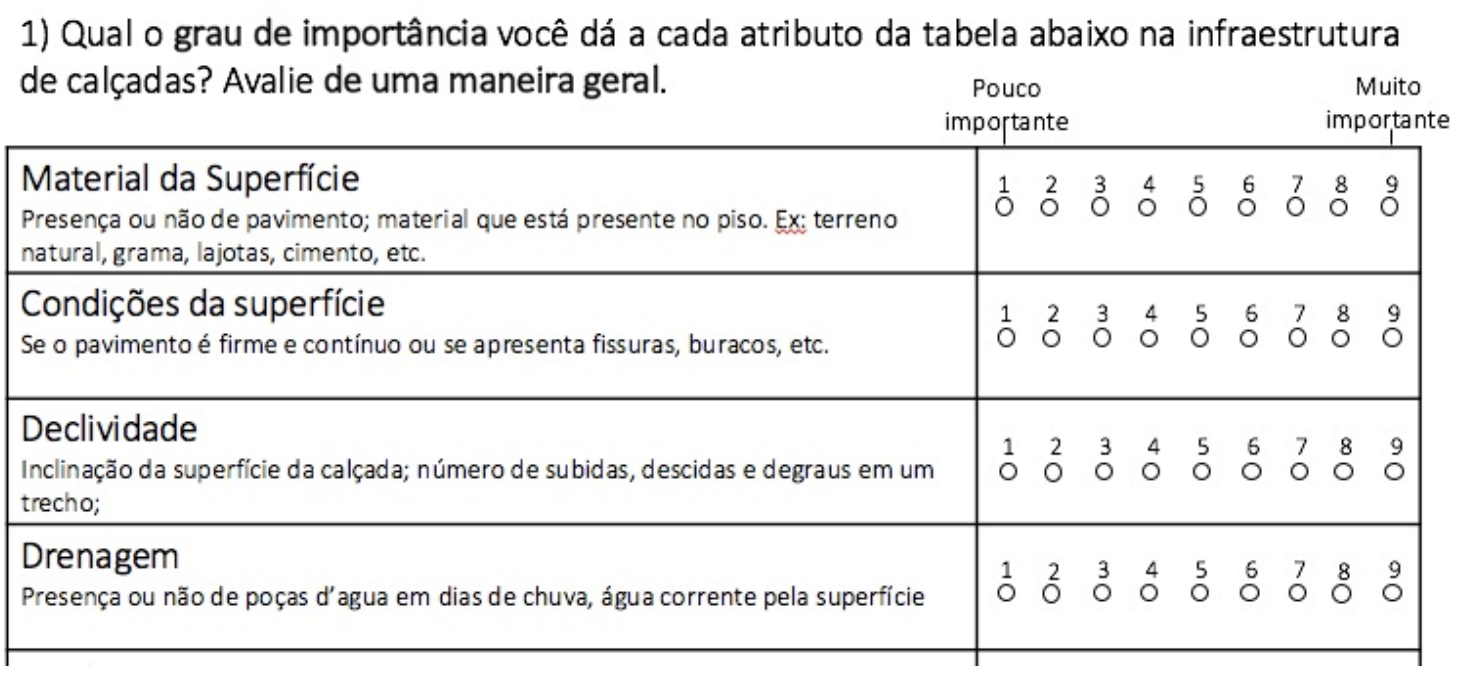

Figura 3. Recorte do instrumento de pesquisa I - Ponderação dos fatores (fonte: elaborada pelos autores).

Foi necessário a execução de duas rodadas na aplicação da técnica Delphi para obtenção da convergência de opiniões obtidas do instrumento de pesquisa I. Dos 212 estabelecimentos, 60 foram questionados na segunda rodada para revisarem suas respostas conhecendo os intervalos determinados pelos valores médios fuzzy dos graus de importância gerais atribuídos pelo grupo. Após essa segunda rodada, todas as respostas ficaram dentro desses intervalos, indicando que o consenso geral tinha sido alcançado, mesmo existindo opiniões diferentes entre os respondentes. A Figura 3 apresenta um recorte do instrumento de pesquisa I utilizado para determinação do grau de importância dos atributos selecionados na RSL, segundo a escala Likert de nove níveis.

Sob a ótica da avaliação de cada atributo segundo a percepção do estado da infraestrutura, a escala utilizada foi de cinco graus de concordância, conforme recorte do questionamento inserido no instrumento de pesquisa II (Figura 4). 
3) Avalie a qualidade da calcada do seu estabelecimento/residência de acordo com os atributos abaixo:

\begin{tabular}{|c|c|}
\hline & Péssima Ótima \\
\hline Material da Superfície & 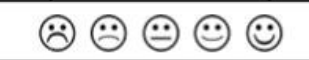 \\
\hline Condições da superfície & $:(:) ;: ;$ \\
\hline Declividade & $:(:) ;: ;$ \\
\hline Drenagem & $:(:) ;: ;$ \\
\hline Sinalização & $:(:) ;(:)$ \\
\hline Iluminação & $:(:) ;: ;:)$ \\
\hline Acessibilidade universal & $:(:) ;: ;$ \\
\hline Largura da calçada & 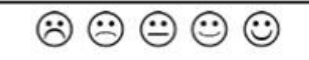 \\
\hline Obstáculos permanentes & $: ;:): ;(;)$ \\
\hline Obstáculos temporários & $:(:) ;: ;)$ \\
\hline
\end{tabular}

Figura 4. Recorte do instrumento de pesquisa II - Avaliação dos atributos (fonte: elaborada pelos autores).

A partir do retorno dos questionários, fez-se a compilação dos dados em uma planilha eletrônica para aplicação da técnica Delphi fuzzy e posteriormente auxiliar o processo de georreferenciamento dos estabelecimentos entrevistados no cenário de estudo. A Figura 5 ilustra as respostas dos 212 estabelecimentos quando questionados sobre o grau de impor- tância de três dos dez atributos (instrumento I) identificados na literatura como de maior destaque: (a) Largura da calçada; (b) Declividade; e (c) Condições da Superfície; para fins de maior compreensão, os dados pontuais encontram-se integrados nos respectivos trechos de calçada. 

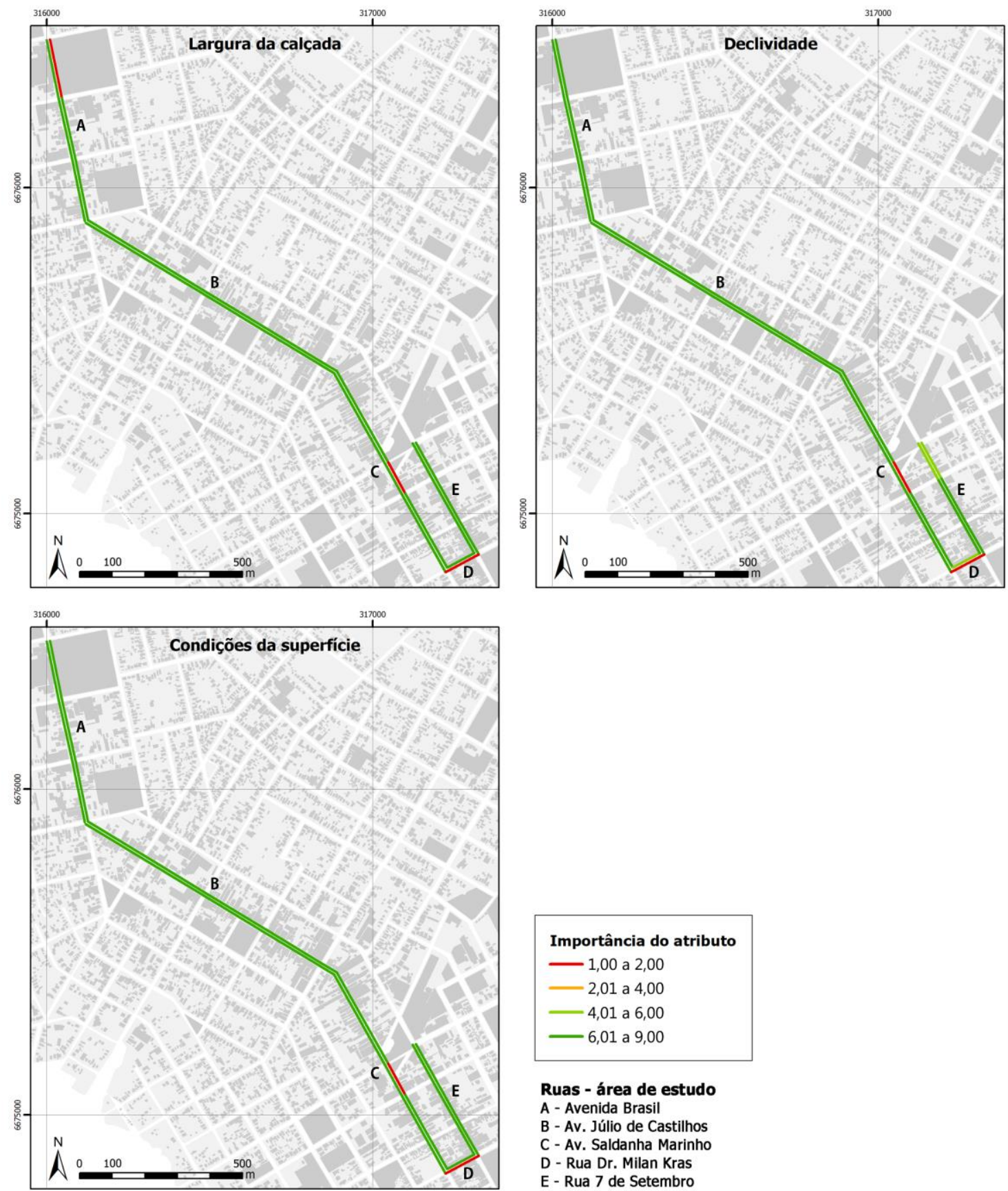

Figura 5. Mapas de importância dos atributos: (a) Largura da calçada, (b) Declividade, (c) Condições da superfície (fonte: elaborada pelos autores).

Em relação aos resultados procedentes do instrumento de pesquisa II, a Figura 6 ilustra igualmente a espacialização das percepções sobre os atributos decorrente das respostas dos
212 estabelecimentos quando questionados sobre a qualidade da calçada dos mesmos três atributos (largura da calçada, declividade e condições da superfície). 

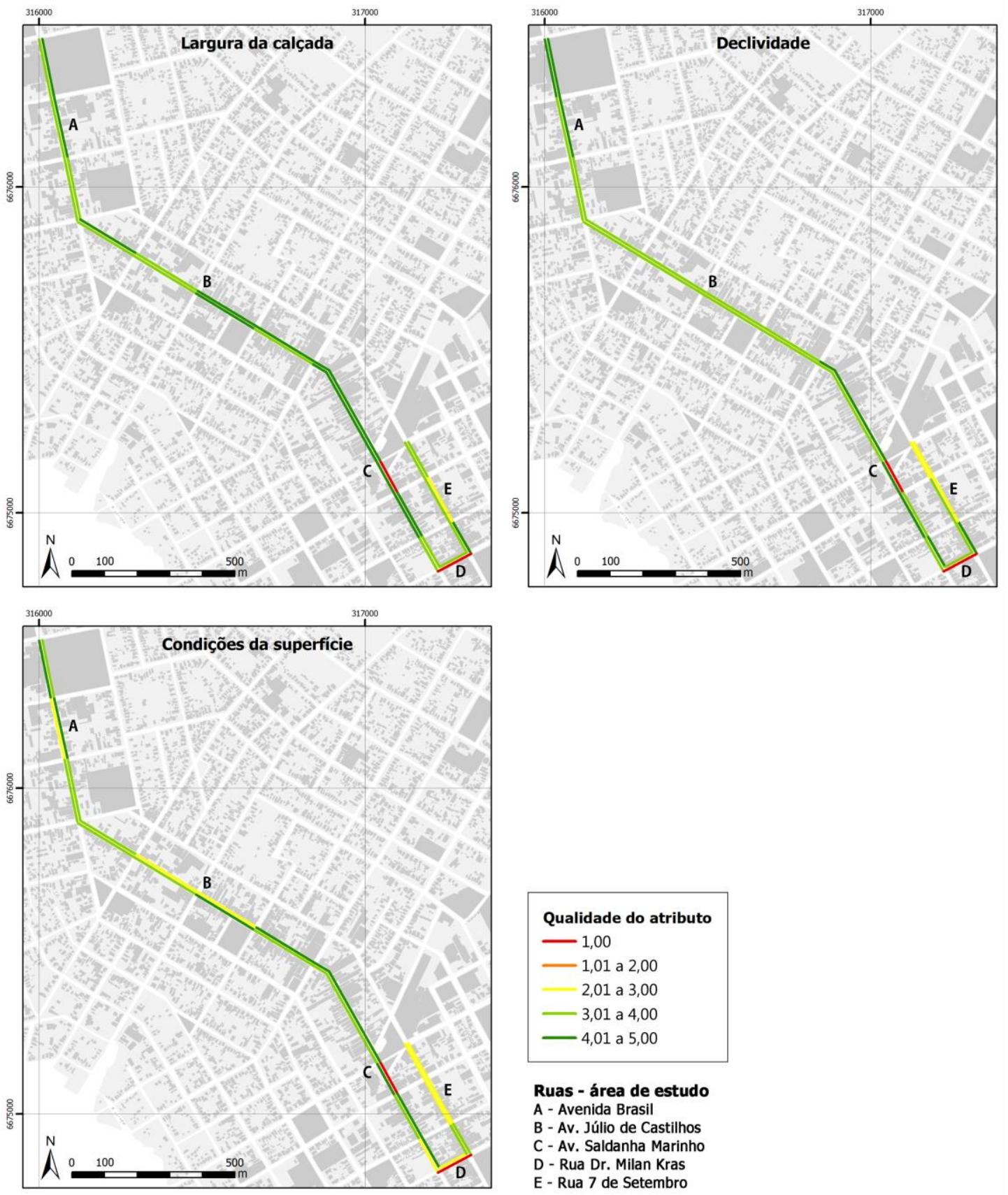

Ruas - área de estudo
A - Avenida Brasil
B - Av. Júlio de Castilhos
C - Av. Saldanha Marinho
D - Rua Dr. Milan Kras
E - Rua 7 de Setembro

Figura 6. Mapas de percepção de qualidade dos atributos: (a) Largura da calçada, (b) Declividade, (c) Condições da superfície (fonte: elaborada pelos autores).

A partir do processamento das respostas compiladas dos questionários foi obtido o valor defuzzificado dos pesos finais, conforme ilustrado na Figura 7, já com dados da importância relativa normalizados em base percentual, desde o ponto de vista dos responsáveis dos estabelecimentos comerciais.

Obtido o ranking de importância geral dos atributos, observa-se que a acessibilidade universal, que tem a função de proporcionar fácil acesso a todas as pessoas, e a largura da calçada, que possibilita a análise da compati- bilidade do dimensionamento com o atual uso do passeio, são considerados os mais importantes. A percepção dos comerciantes pode estar atrelada com o conforto que esses atributos podem trazer ao ambiente viário. A largura da calçada tem relação direta com o nível de serviço percebido, pois espaços amplos trazem conforto e estimulam as atividades de pedestres, assim como facilitam a acessibilidade em geral para todos os usuários. Lima e Machado (2019), em um estudo na cidade de Itajubá - MG, evidenciaram que, segundo as 
ponderações por parte de pessoas com mobilidade reduzida, a largura da calçada e demais aspectos de geometria têm o maior impacto no acesso individual e maior importância do que outros grupos. Já Bentzen et al. (2020) ressal- taram a importância da presença de dispositivos que promovem acessibilidade e de verificar quais elementos trarão menor impacto e esforço para estes usuários.

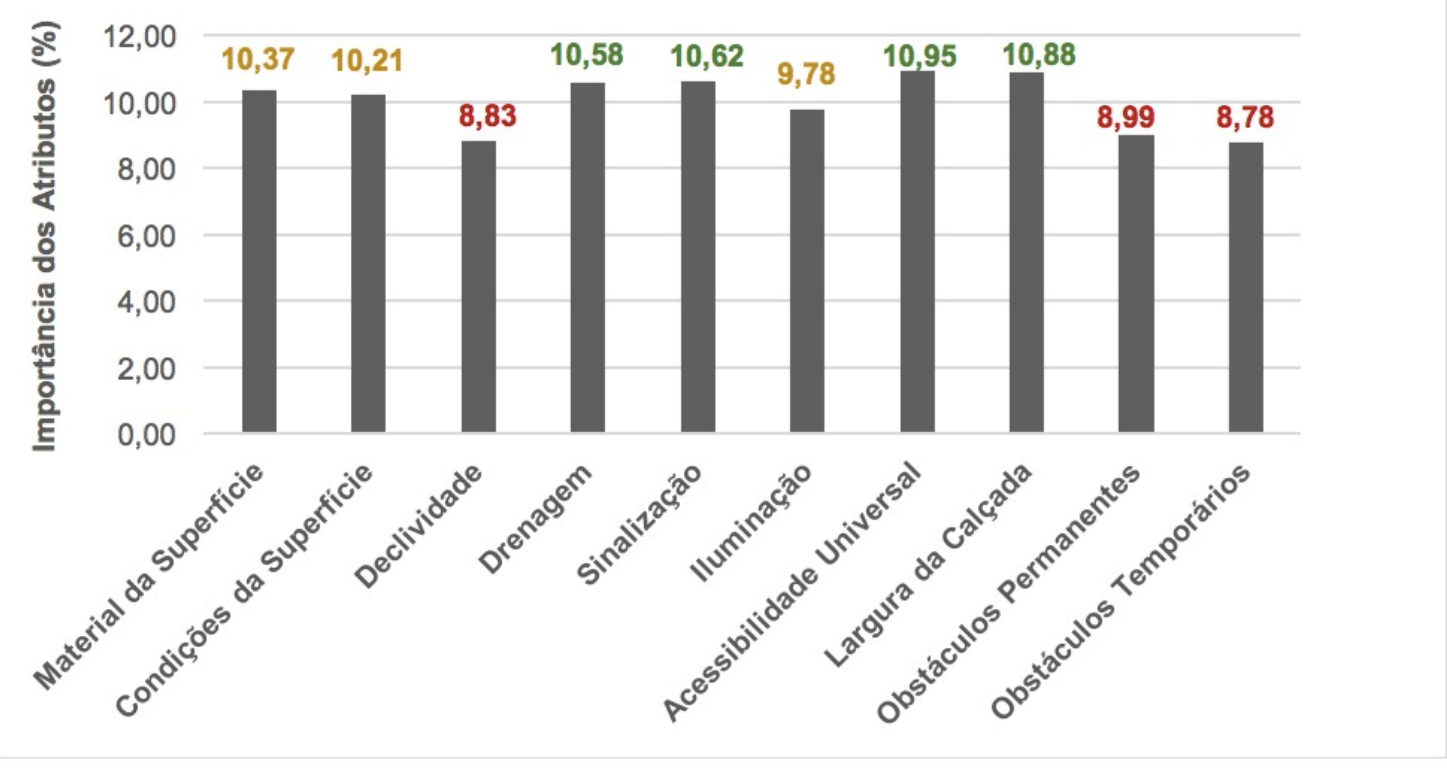

Figura 7. Importância relativa dos Atributos (\%) calculada por Delphi-Fuzzy (fonte: elaborada pelos autores).

Considerados atributos de importância mediana, encontram-se os valores conferidos à condição do pavimento e material da superfície. Todavia, ainda que tenham ficado em segundo plano, esses atributos estão relacionados à carência de infraestrutura nas calçadas, situação presente em diversas cidades brasileiras. Hallal, Reis e Parra (2010) destacam em um estudo realizado em Recife$\mathrm{PE}$, que as condições da superfície afetam os deslocamentos a pé, e influenciam diretamente nas atividades físicas nos locais estudados. Já uma pesquisa realizada em 11 cidades da América Latina identificou que uma infraestrutura adequada para pedestres, onde inclui-se calçadas e vias pavimentadas, é tida como um dos atributos de maior importância para a atratividade dos bairros e uso de parques para atividades de lazer (Moran et al., 2020). Esses relatos reforçam a necessidade de políticas públicas voltadas para a melhoria dos materiais e das condições das superfícies das calçadas em cidades da América Latina.

Sobre os atributos referentes à declividade e aos obstáculos temporários e permanentes, que obtiveram menor relevância nesta pesquisa, pode-se atribuir essa estimativa à relação feita pelos avaliadores de acordo com as condições locais, consideradas não críticas. Nesse sentido, Hermida, Cordero e Orellana (2019), que avaliaram a influência do ambiente construído no fluxo de pedestres em uma cidade de médio porte nos Andes do Equador, identificaram que obstáculos como árvores, sinais de trânsito, postes de luz e pontos de ônibus afetam fortemente o comportamento de caminhada e segurança dos pedestres, principalmente no caso de idosos e pessoas com mobilidade reduzida, e que a remoção destes pode ser uma estratégia simples, efetiva e complementar na busca por uma melhor infraestrutura para os pedestres.

Já o estudo realizado por Golan et al. (2019), na cidade de São Francisco (EUA), analisou a declividade por meio de grupos respondentes, que avaliaram a inclinação como um fator influente em seus deslocamentos. Esse parecer pode estar associado ao terreno montanhoso da cidade, porém, os autores sugeriram uma nova análise para ver como se daria essa classificação se fosse apresentado um cenário 
hipotético em que o relevo da cidade fosse plano. Se opondo a isso, a opinião dos comerciantes de Cachoeira do Sul pode estar diretamente ligada à questão da topografia do local, já que o local não apresenta grandes elevações, sendo considerado relativamente plano.

Os resultados da ponderação dos atributos do ponto de vista dos responsáveis dos estabelecimentos foram comparados aos obtidos a partir da percepção dos usuários das vias, analisada a partir dos dados coletados através de entrevistas. As questões apresentadas aos usuários buscaram identificar a importância relativa dos três atributos do ambiente físico que influenciam a caminhabilidade, conforme reportado no estudo de Oestreich et al. (2018), visando o processamento dos dados com a Social Choice Function. Assim, cada respondente classificou os atributos conforme seu julgamento de importância para a caminhada, e a aplicação do método Schulze permitiu obter um ranqueamento da importância dos atributos. Do mesmo modo, foi possível obter o valor de importância normalizado atribuído conforme as ponderações dos respondentes, que foi a seguinte: condições da superfície $(13,21 \%)$, declividade $(9,64 \%)$, largura da calçada $(7,05 \%)$.

Comparando esses resultados com aqueles obtidos para os estabelecimentos (Figura 7) nestes três atributos, é verificado que a ordenação é diferente: largura da calçada $(10,88 \%)$, condições da superfície $(10,21 \%)$ e declividade $(8,83 \%)$. Percebe-se assim que, para os estabelecimentos, a largura da calçada é o fator mais importante, enquanto que para os usuários das vias este é o atributo menos importante, sendo que o atributo condições da superfície, seguido da declividade do terreno, tem uma importância maior.

$\mathrm{O}$ atributo largura da calçada pode ser entendido como um fator que torna atrativa a caminhada nos espaços urbanos, além de aumentar a capacidade de fluxo de pedestres, ou seja, mais pessoas têm acesso aos estabelecimentos comerciais do entorno. Isso explica a priorização do atributo por parte dos estabelecimentos, enquanto que os usuários das vias (os pedestres) estão mais interessados na garantia de condições adequadas da superfície das calçadas, seguida da declividade, que pode trazer um conforto a mais na caminhada.
Dessa maneira, percebe-se que os responsáveis dos estabelecimentos e os usuários ponderam a importância dos atributos para a caminhada de forma diferente, conforme seus benefícios específicos. As diferenças entre as percepções dos comerciantes e dos pedestres quanto à importância dos atributos relativos à infraestrutura das calçadas, identificadas a partir dessas observações empíricas no cenário de estudo, evidenciam a necessidade de uma ferramenta de avaliação consensuada que possa garantir o equilíbrio entre as estratégias para melhorar a caminhada. Além disso, salientam a importância da atuação da comunidade para garantir que os critérios para tomada de decisão nos projetos de mobilidade sejam condizentes com as suas necessidades (Makarewicz et al., 2018).

\section{Avaliação da qualidade das calçadas}

O método empregado para elaboração do índice de qualidade das calçadas no estudo, depois de feitas as devidas ponderações e avaliação dos atributos, se sucedeu por meio da função de agregação aditiva entre o grau de importância e a percepção do indicador na área de estudo, normalizados a partir do grau de importância dos atributos, como mostra a Equação 3.

$$
I q c=\frac{\sum_{n=1}^{10} g i_{n} \times a_{n}}{\sum_{n=1}^{10} g i_{n}}
$$

Onde:

$I q c:$ índice de qualidade das calçadas;

$g i_{n}$ : grau de importância do atributo n;

$a_{n}$ : percepção da qualidade da calçada no atributo $\mathrm{n}$.

Assim, o índice de qualidade das calçadas obtido, representado espacialmente na Figura 8 , demonstra que, de maneira geral, a qualidade das calçadas da área estudada está em boas condições. Todavia, esse resultado, decorrente da interpretação do índice ponderado, que faz a associação aditiva das percepções, formando um único valor, agrega as características pontuais dos trechos, destacando aqueles em que há necessidade de intervenção, pois apresentaram baixo conceito. Isso reitera a importância dos resultados e dos dados de origem estarem georreferenciados, pois traz também a possibilidade de explorar individualmente cada atributo de maneira clara, visual e intuitiva. 


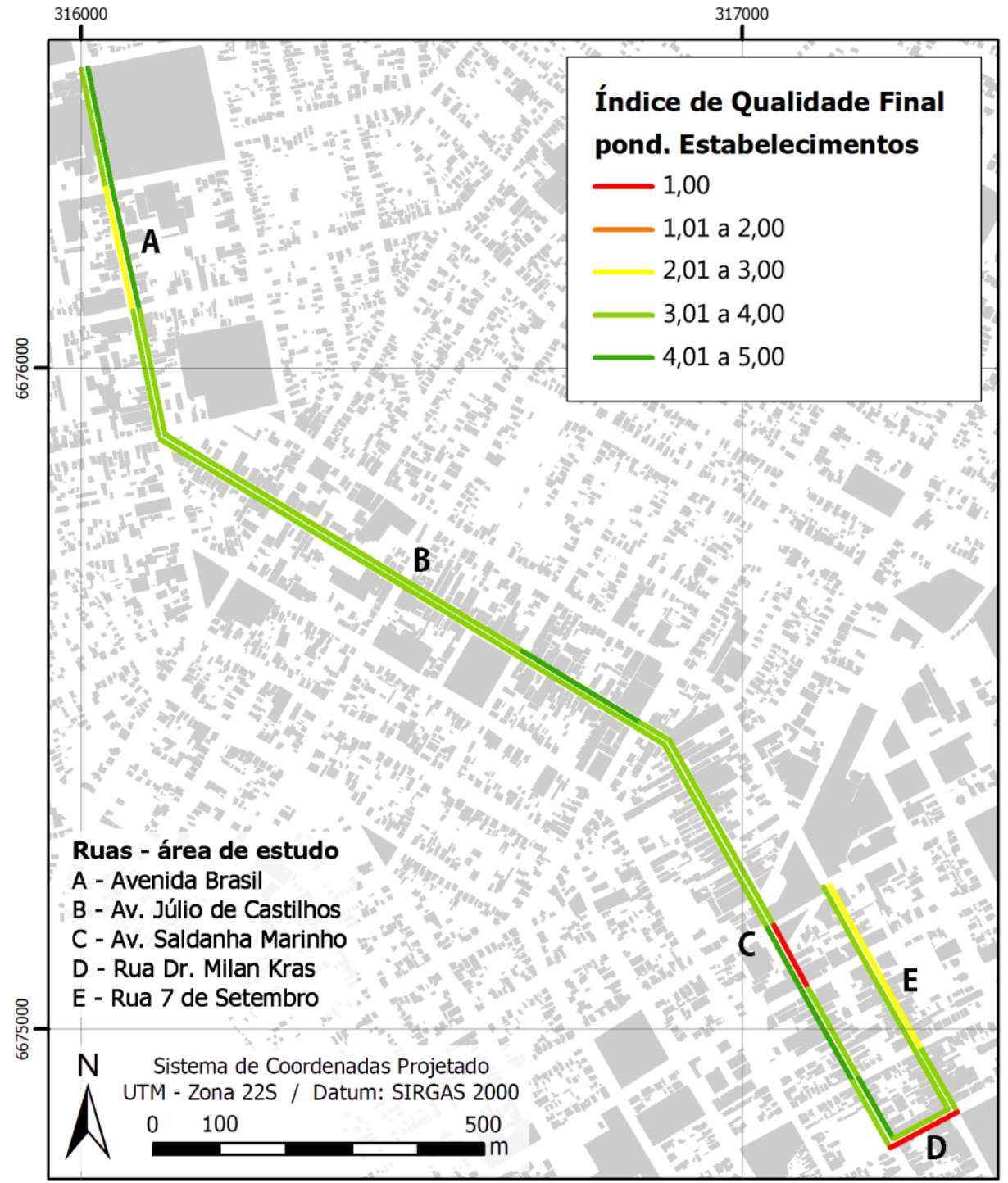

Figura 8. Mapa do Índice de Qualidade Final das calçadas (fonte: elaborada pelos autores).

Analisando pormenorizadamente os resultados, é possível verificar que, na porção norte do eixo A, representando a Avenida Brasil, a iluminação foi um atributo percebido com boa qualidade, evidenciando que as calçadas à noite são bem visíveis (Figura 9-A2), tornando o ambiente mais seguro para os deslocamentos a pé. Isto contribui para o elevado índice de qualidade obtido. Já a qualidade intermediária do passeio encontrada em um dos trechos do eixo A, deve-se ao fato do pavimento, naquele local, não estar em plenas condições de conservação e estado (Figura 9A1).
A Avenida Júlio de Castilhos (eixo B), que contempla, efetivamente, a maior concentração de estabelecimentos, tem como destaque boas percepções referentes às condições da superfície e largura das calçadas (Figuras 9B1 e 9-B2). Ao longo de todo o espaço, os pedestres podem transitar com segurança, conforto, sem a interferência de obstáculos, sejam eles permanentes ou temporários, além de se configurar um ambiente atrativo, por conta do número de vitrines e serviços ofertados. 


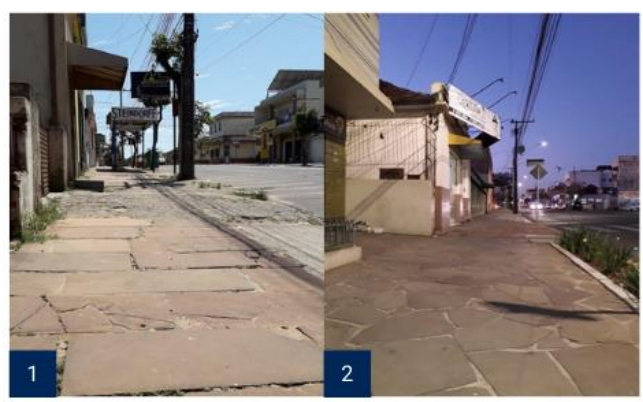

A - Avenida Brasil

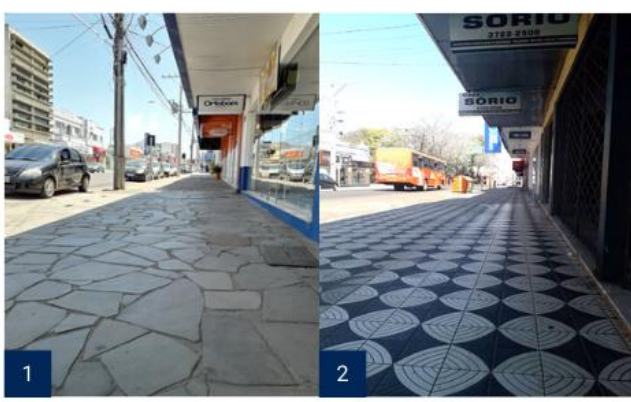

B - Av. Júlio de Castilhos

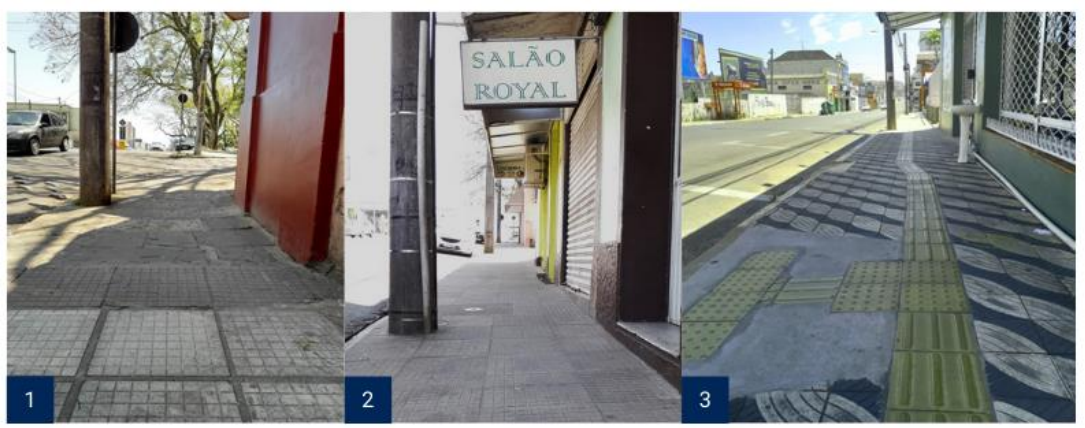

C - Av. Saldanha Marinho

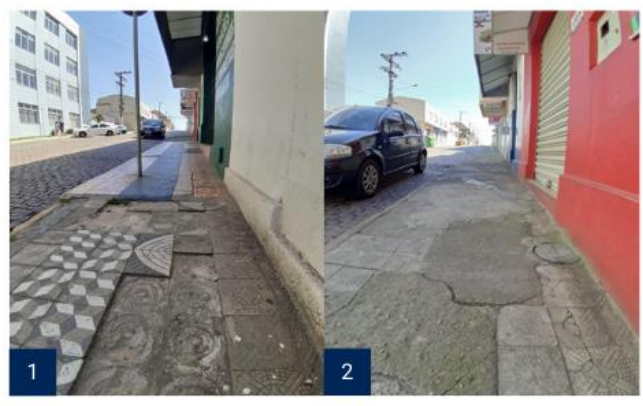

D - Rua Dr. Milan Krás

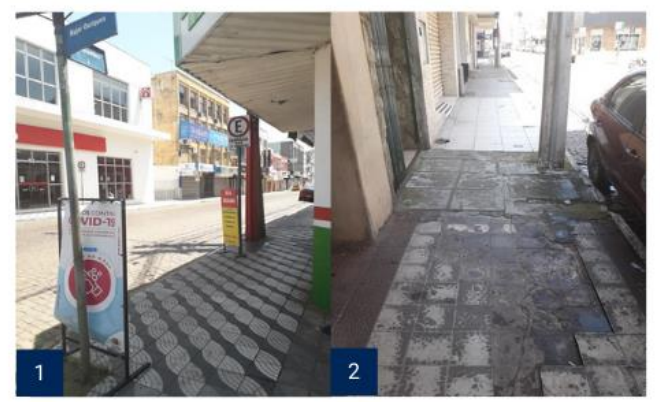

E - Rua 7 de Setembro

Figura 9. Situação in loco dos passeios (fonte: elaborada pelos autores).

Sobre a Avenida Saldanha Marinho (eixo C), o trecho representado pela menor qualidade é decorrente da má condição da superfície (Figura 9-C1), da presença de obstáculos permanentes (Figura 9-C1 e 9-C2) e da deficiência de dispositivos de drenagem, visto que a via está a certo nível acima do passeio (Figura 9C2) e, quando ocorrem chuvas intensas, as calçadas acumulam água e tornam-se inapropriadas para pedestres. Porém, a acessibilidade universal, considerada como atributo de grande importância em toda região estudada, é presente no eixo através de rampas e piso tátil (Figura 9-C3), o que faz melhorar o índice de qualidade geral.

No eixo D, localizado na Rua Dr. Milan Krás, os atributos percebidos com maior nível de precariedade referem-se às condições da su- perfície e ao material da superfície. Neste local diversas calçadas encontram-se com problemas na estrutura física e no estado de conservação do piso (Figuras 9-D1 e 9-D2), gerando desconforto e insegurança nos deslocamentos dos pedestres. Já no eixo E, pertencente à Rua 7 de Setembro, as calçadas são mais estreitas e, em muitos pontos, devido à presença de obstáculos permanentes e temporários (Figura 9-E1), têm sua capacidade ainda mais reduzida. As condições do pavimento (Figura 9-E2) também evidenciam a necessidade de conceder atenção a esse atributo, de forma que a avalição ponderada geral não é satisfatória.

Por fim, foi possível observar que houve certa diferença entre a avaliação sobre a qualidade das calçadas ao longo do trecho estudado, 
reafirmando que os resultados estão relacionados com a percepção das condições da calçada de cada local. Assim, a metodologia utilizada fornece resultados adequados se comparados com a realidade do local observado, o que destaca a importância do estudo para tomada de decisões dos gestores, identificando e traçando planos de ação e implementação de políticas públicas de melhoria ou fiscalização dos atributos nas calçadas.

\section{Análise de sensibilidade do índice de qualida- de das calçadas}

A análise de sensibilidade, posta em discussão neste estudo, propôs-se a verificar a variação do índice de qualidade das calçadas devido às mudanças do grau de importância de três dos dez atributos. Sob a ótica referencial clássica, a análise de sensibilidade surgiu ao perceber que o risco poderia ser analisado a contento, bastando que se fornecesse a faixa de variação associada a cada elemento do modelo (House, 1968). Isto é, torna-se possível obter simulações sobre o efeito do modelo considerando variações nos seus elementos de entrada.

Diante disso, considerando a percepção de importância dada pelos proprietários dos estabelecimentos, comparada à opinião dos usuários, levando em conta os resultados obtidos anteriormente, tem-se o mapa da Figura 10.

Na perspectiva do modelo proposto, o desempenho global da calçada relaciona-se diretamente à importância dada aos parâmetros analisados na forma de pesos relativos pelos responsáveis dos estabelecimentos. Nesse sentido, a análise de sensibilidade do modelo procurou estimar o resultado final do desempenho da qualidade das calçadas de acordo com variação dos pesos das três variáveis avaliadas pelos usuários do trecho. Isto é, a análise de sensibilidade proposta aqui propõe perceber quão sensível comporta-se o modelo ao variar o grau de importância de fatores específicos. Foram analisados 202 pontos georreferenciados no cenário de estudo e, em apenas 43 destes, a qualidade na ótica dos usuários (pedestres) foi maior do que a percepção dos comerciantes. Os outros 159 pontos foram mais bem avaliados pelos estabelecimentos, responsáveis diretos pela conservação e manutenção da calçada. Contudo, a análise de sensibilidade não foi significativa na alteração do resultado global da qualidade. Isto é, em média, a alteração por ponto foi de $+0,51 \%$ com desvio padrão de 0,014 . Ou seja, se o modelo alterasse o peso dos atributos sobreditos para a percepção dos usuários, a resposta global do índice de qualidade das calçadas seria alterada de forma insignificante para $+0,51 \%$ com desvio padrão de 0,014 . A exemplo disso, uma quadra com avaliação 1,0 passaria a ser avaliada com índice 1,0051.

Percebe-se que, se a avaliação fosse feita considerando apenas a percepção dos usuários, a qualidade das calçadas não seria perturbada na saída do modelo. Diante da baixa amplitude de opiniões é possível evidenciar a caracterização equânime na percepção da qualidade da calçada, verificada pelos responsáveis dos estabelecimentos e os usuários, o que torna robusto o modelo proposto e fiável para sua utilização na tomada de decisões por parte dos gestores responsáveis. Para isso, a metodologia permite visualizar e hierarquizar quais localidades necessitam intervenções de melhoria imediatas, através dos valores do índice de qualidade, bem como aferir os atributos que mais influenciam, de forma positiva ou negativa, na construção desse índice. Além disso, o modelo pode ser replicado na sua forma completa, com apoio do georreferenciamento dos dados, possibilitando analisar de forma clara e visual a situação de cada passeio e de cada atributo de maneira individual, ou de forma reduzida, analisando os atributos exclusivamente de forma numérica através das técnicas utilizadas ou, ainda, com suporte nos pesos calculados nesse estudo. 


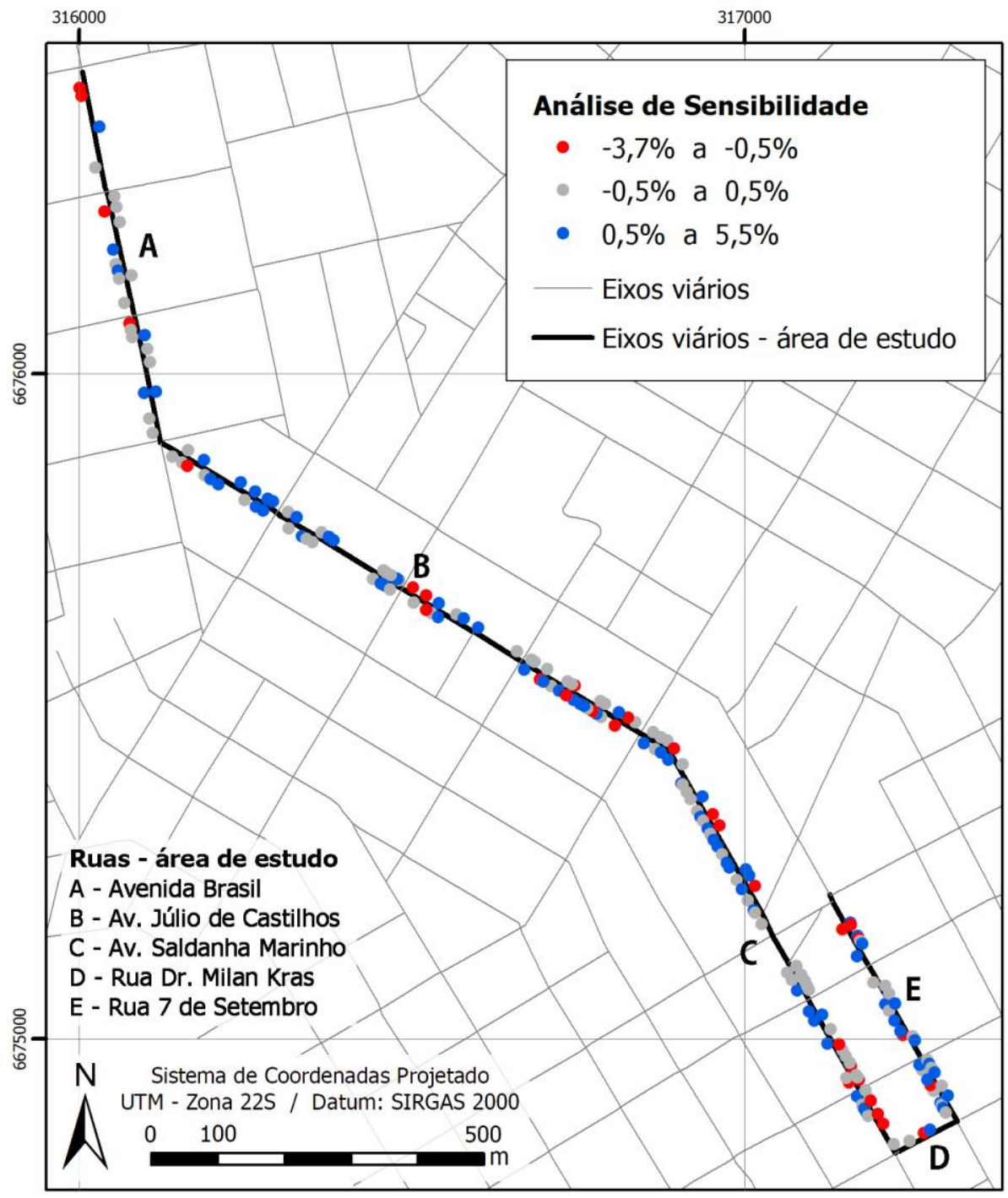

Figura 10. Análise de Sensibilidade (fonte: elaborada pelos autores).

\section{Conclusões}

Para promover a caminhada como meio de transporte sustentável nas cidades, é necessário prover condições adequadas para esses deslocamentos. Este estudo propôs a apresentação de uma metodologia híbrida de avaliação da infraestrutura das calçadas que combina técnicas geoespaciais e analíticas relacionadas a técnica Delphi, lógica fuzzy e Social Choice Functions para averiguar medidas que podem ser aplicadas para a melhoria das condições da caminhada.

O método integra dados de percepções dos responsáveis dos estabelecimentos comerciais e também dos usuários das vias (pedestres) sobre aspectos relacionados à caminhabilidade, definidos a partir da revisão sistemática da literatura. A partir deles, foi elaborado um índice ponderado de qualidade das calçadas levando em consideração dez atributos. Adicionalmente, análises geoespaciais auxiliaram na criação de mapas temáticos do índice de qualidade das calçadas e na análise de sensibilidade dos resultados, agregando as discussões do ponto de vista espacial.

Como resultados, o comparativo das importâncias com base nos atributos em comum das percepções dos estabelecimentos e os usuários das vias mostrou que existem diferenças, ainda que pequenas, na ordem de importância dos atributos que podem estar atreladas aos seus interesses. Enquanto que os usuários consideram que as condições do pavimento da superfície é o atributo mais importante, os responsáveis por estabelecimentos acreditam que a maior relevância é da largura da calçada. Este último pode ser entendido como um atributo que aumenta a capacidade das vias, 
trazendo mais conforto aos pedestres, enquanto que as condições do pavimento afetam a possibilidade de caminhar nas vias e as descontinuidades podem desestimular seu uso.

Embora relatadas essas diferenças de percepções, a análise de sensibilidade aplicada ao índice proposto mostrou uma baixa amplitude nas avaliações dos responsáveis dos estabelecimentos e dos usuários, evidenciando que se trata de opiniões que têm relação direta com suas percepções. Portanto, a aplicação do índice de qualidade das calçadas mostra que a metodologia empregada condiz com as condições vivenciadas nas vias, corroborando com a adequabilidade do método. Ainda que esta pesquisa não permita generalizar conclusões sobre as condições das calçadas para toda a cidade e nem para outros locais, os resultados são suficientemente promissores e estatisticamente comprovados para serem levados em consideração e aplicados em outras realidades, podendo auxiliar na gestão do planejamento urbano.

Assim, com base nas evidências empíricas reportadas, o método apresentado permite que planejadores urbanos possam verificar a importância de atributos para a caminhada, além de verificar as condições desses atributos nas vias. Esses resultados podem auxiliar no processo decisório de planejamento e implemen-

\section{Referências}

Aghaabbasi, M., Moeinaddini, M., Shah, M. Z. e Asadi-Shekari, Z. (2017) A new assessment model to evaluate the microscale sidewalk design factors at the neighbourhood level. Journal of Transport $e$ Health. 5, 97-112. Disponível em: http://dx.doi.org/10.1016/j.jth.2016.08.012

Associação Nacional de Transportes Públicos ANTP (2016) Sistema de Informações da Mobilidade Urbana da Associação Nacional de Transportes Público - Simob/ANTP. Disponível em: http://files.antp.org.br/simob/simob-2016-v6.pdf. [Consultado em: 11 de setembro de 2020].

Associação Nacional de Transportes Públicos ANTP (2017) Mobilidade Humana para um Brasil Urbano. Disponível em: http://files.antp.org.br/2017/7/12/antp-mobilidadehumana-11-07-2017--baixa.pdf. [Consultado em: 11 de setembro de 2020].

Banister, D. (2008) The sustainable mobility paradigm. Transport Policy. 15(2), 73-80. Disponível em: https://doi.org/10.1016/j.tranpol.2007.10.005

Battista, G. A. e Manaugh, K. (2019) Generating walkability from pedestrians' perspectives using a tação de políticas públicas de melhoria ou fiscalização. Como propostas para trabalhos futuros, sugere-se abranger outros bairros e cidades com características diferentes, como forma de verificar a adaptação do método a outras realidades. Também, sugere-se que sejam levadas em consideração as percepções de outros atributos do ponto de vista daqueles que utilizam usualmente as vias, assim como estudos que possam comparar situações antesdepois de medidas de melhoria ou reforma das calçadas.

\section{Agradecimentos}

Os autores agradecem a colaboração dos comerciantes e cidadãos de Cachoeira do Sul que participaram na pesquisa. Também agradecem ao editor e aos avaliadores por seus valiosos comentários que ajudaram a melhorar o artigo. Letícia Oestreich agradece ao Conselho Nacional de Desenvolvimento Científico e Tecnológico (CNPq) pela bolsa de iniciação científica PIBIC. Bárbara Maria Giaccom Ribeiro agradece ao $\mathrm{CNPq}$ pelo apoio financeiro (Processo 437313/2018-2). Alejandro Ruiz-Padillo agradece ao $\mathrm{CNPq}$ pelo apoio financeiro (Processo 308870/20182 e Processo 422635/2018-9).

qualitative GIS method. Travel Behaviour and Society. 17, 1-7. Disponível em: https://doi.org/10.1016/j.tbs.2019.05.009

Batty, M. (2004) A new theory on Space Syntax. UCL Working Paper Series. 75, 1-36. Disponível em:

https://www.ucl.ac.uk/bartlett/casa/sites/bartlett/fil es/migrated-files/paper75_0.pdf. [Consultado em: 09 de setembro de 2020].

Bentzen, B. L., Scott, A. C., Emerson, R. W. e Barlow, J. M. (2020) Effect of Tactile Walking Surface Indicators on Travelers with Mobility Disabilities. Transportation Research Record: Journal of Transportation Research Board. 2674(7), 410-419. Disponível em: https://doi.org/10.1177/0361198120922995

Bivina, G.R., Parida, P., Advani, M. e Parida, M. (2018) Pedestrian Level of Service Model for Evaluating and Improving Sidewalks From Various Land uses. European Transport 1 Trasporti Europei. 67, 2. Disponível em: http://www.istiee.unict.it/europeantransport/papers /N67/P02_67_2018a.pdf. [Consultado em: 13 de setembro de 2020]. 
Câmara, G., Davis, C. e Monteiro, A. M. V. (2001) Introdução à Ciência da Geoinformação. São José dos Campos, INPE. Disponível em: http://mtcm12.sid.inpe.br/col/sid.inpe.br/sergio/2004/04.22.0 7.43/doc/publicacao.pdf. [Consultado em: 09 de setembro de 2020].

Cervero, R. (1996) Mixed land-uses and commuting: Evidence from the American Housing Survey. Transportation Research Part A: Policy and Practice. 30(5), 361-377. Disponível em: https://doi.org/10.1016/0965-8564(95)00033-X

Cervero, R. e Duncan, M. (2003) Walking, Bicycling, and Urban Landscapes: Evidence from the San Francisco Bay Area. American Journal of Public Health. 93(9), 1478-1483. Disponível em: https://doi.org/10.2105/AJPH.93.9.1478

Chan, E. T. H., Schwanen, T. e Banister, D. (2019) The role of perceived environment, neighbourhood characteristics, and attitudes in walking behaviour: evidence from a rapidly developing city in China. Transportation. Disponível em: https://doi.org/10.1007/s11116-019-10062-2

Csar, T., Lackner, M. e Pichler, R. (2018) Computing the Schulze Method for Large-Scale Preference data Sets. Proceedings of the Twenty-Seventh International Joint Conference on Artificial Intelligence. 180-187. Disponível em: https://doi.org/10.24963/ijcai.2018/25

Doescher, M. P., Lee, C., Berke, E. M., AdachiMejia, A. M., Lee, C., Stewart, O., Patterson, D. G., Hurvitz, P. M., Carlos, H. A., Duncan, G. E. e Moudon, A. V. (2014) The built environment and utilitarian walking in small U.S. towns. Preventive Medicine. 69, 80-86. Disponível em: https://doi.org/10.1016/j.ypmed.2014.08.027

D'Orso, G. e Migliore, M. (2020) A GIS-based method for evaluating the walkability of a pedestrian environment and prioritised investments. Journal of Transport Geography. 82, 102555. Disponível https://doi.org/10.1016/j.jtrangeo.2019.102555

Ewing, R. e Cervero, R. (2001) Travel and the Built Environment: A Synthesis. Transportation Research Record: Journal of Transportation Research Board. 1780(1), 87-114. Disponível em: https://doi.org/10.3141/1780-10

Faria, A. P. N. de (2010) Categorias FísicoEspaciais Definidoras da Qualidade Urbana. 249 p. Porto Alegre, 2010. Tese (Doutorado em Planejamento Urbano e Regional). Porto Alegre: UFRGS - Universidade Federal do Rio Grande do Sul, Programa de Pós-graduação em Planejamento Urbano e Regional, Departamento de Urbanismo, Faculdade de Arquitetura, 2010.

Ferreira, M. A. G. e Sanches, S. da P. (2001) Índice de Qualidade das Calçadas - IQC. Revista dos
Transportes Públicos. 23(2), 47-60. Disponível em:

https://mobilidadeape.files.wordpress.com/2015/05 /c3adndice-de-qualidade-das-calc3a7adas-antp.pdf [Consultado em: 10 de setembro de 2020].

Francis, M. (1987) Urban Open Spaces. In: Zube, E.; Moore, G. T. (eds.), Advances in environment, behaviour, and design. New York, EUA: Plenum Press. p. 71-102.

Gehl, J. (2013) Cidades para pessoas. São Paulo, Editora Perspectiva.

Ghidini, R. (2011) A caminhabilidade: medida urbana sustentável. Revista dos Transportes Públicos. 33(1), 23-33. Disponível em: http://filesser-

ver.antp.org.br/_5dotSystem/download/dcmDocu ment/2013/01/10/CF0ED9C9-0025-4F55-8F7CEDCB933E19C4.pdf [Consultado em: 10 de setembro de 2020].

Golan, Y., Wilkinson, N. L., Henderson, J. e Weverka, A. (2019) Gendered walkability: Building a daytime walkability index for Women. The Journal of Transport and Land Use. 12 (1), 501-526. Disponível

em: http://dx.doi.org/10.5198/jtlu.2019.1472

Guimarães Silva, K., Favarão Leão, A. L., Ragassi Urbano, M. e Kanashiro, M. (2019) Percepções do ambiente construído e sua associação com a caminhabilidade objetiva. Revista de Morfologia Urbana, 7(2), e00084. DOI: https://doi.org/10.47235/rmu.v7i2.84

Hallal, P. C., Reis, R. S., Parra, D. C. (2010) Association Between Perceived Environmental Attributes and Physical Activity Among Adults in Recife, Brazil. Journal of Physical Activity and Health, 7(s2), 13-22. Disponível em: https://doi.org/10.1123/jpah.7.s2.s213

Hermida, C., Cordero, M. e Orellana, D. (2019) Analysis of the influence of urban built environment on pedestrian flow in an intermediate-sized city in the Andes of Ecuador. International Journal of Sustainable Transportation. 13:10, 777-787. Disponível https://doi.org/10.1080/15568318.2018.1514445

Herrmann-Lunecke, M. G., Mora, R. e Sagaris, L. (2020) Persistence of walking in Chile: lessons for urban sustainability. Transport Reviews. 40:2, 135159. Disponível em: https://doi.org/10.1080/01441647.2020.1712494

Hillier, B. (1996) Space is the machine. Londres, Reino Unido: Space Syntax.

Hillier, B. e Hanson, J. (1984) The Social Logic of Space. Cambridge, Reino Unido: Cambridge University Press. 
Hillier, B., Penn, A., Hanson, J., Grajewski, T. e $\mathrm{Xu}$, J. (1993) Natural movement: or, configuration and attraction in urban pedestrian movement. Environment and Planning B: Planning and Design, 20, 29-66.

House, W. C. (1968) Sensitivity analysis in making capital investment decisions. New York, National Association of Accountants.

Hsieh, T., Lu, S. e Tzeng, G. (2004) Fuzzy MCDM approach for planning and design tenders selection in public office buildings. International Journal of Project Management. 22(7), 573-584. Disponível em:

https://doi.org/10.1016/j.ijproman.2004.01.002

Instituto Brasileiro de Geografia e Estatística IBGE (2012) Perfil dos municípios brasileiros 2011. Disponível em: ftp:ftp.ibge.gov.br/Perfil_Municipios/2011/munic2 011.pdf. [Consultado em: 26 de agosto de 2020].

Instituto de Políticas de Transporte e Desenvolvimento - ITDP (2019) Índice de caminhabilidade Ferramenta versão 2.0. Disponível em: itdpbrasil.org/icam2/ [Consultado em: 26 de abril de 2021].

Jiang, B. e Claramunt, C. (2002) Integration of space syntax into GIS: new perspectives for urban morphology. Transactions in GIS, Oxford, 6, (3), 295-309.

Kelly, C. E., Tight, M. R., Hodgson, F. C. e Page, M. W. (2011) A comparison of three methods for assessing the walkability of the pedestrian environment. Journal of Transport Geography. 19(6), 1500-1508. Disponível em: https://doi.org/10.1016/j.jtrangeo.2010.08.001

Kim, S., Park, S. e Lee, J. S. (2014) Meso- or micro-scale? Environmental factors influencing pedestrian satisfaction. Transportation Research Part D: Transport and Environment. 30, 10-20. Disponível https://doi.org/10.1016/j.trd.2014.05.005

Konu, H. (2015) Developing nature-based tourism products with customers by utilising the Delphi method. Tourism Management Perspectives. 14, 42-54. Disponível em: https://doi.org/10.1016/j.tmp.2015.03.003

Krykhtine, F. L. P., Morim, A. C. D., Vale, N. G. P. do, Fortes, L. E. N. S. e Neto, A. G. C. (2013) Aplicando Lógica Fuzzy em um Modelo de Seleção Multicritério para Multiclientes. Em: X SEGeT - Simpósio de Gestão e Excelência em Tecnologia. Resende, SEGeT 2017, 24-26 outubro de 2017, Resende, Brasil. Disponível em: https://www.aedb.br/seget/arquivos/artigos13/4751 8707.pdf. [Consultado em: 12 de setembro de 2019].
Lamour, Q., Morelli, A. M. e Marins, K. R. de C. (2019) Improving walkability in a TOD context: Spatial strategies that enhance walking in the Belém neighbourhood, in São Paulo, Brazil. Case Studies on Transport Policy. 7, 280-292. Disponível

em: https://doi.org/10.1016/j.cstp.2019.03.005

Larrañaga, A. M., Arellana, J., Rizzi, L. I., Strambi, O. e Cybis, H. B. B. (2019) Using best-worst scaling to identify barriers to walkability: a study of Porto Alegre, Brazil. Transportation. 46, 2347 $2379 . \quad$ Disponível em: https://doi.org/10.1007/s11116-018-9944-X

Lee, J., Abdel-Aty, M. e Shah, I. (2019) Evaluation of surrogate measures for pedestrian trips at intersections and crash modeling. Accident Analysis and Prevention. 130, 91-98. Disponível em: https://doi.org/10.1016/j.aap.2018.05.015

Li, J., Auchincloss, A. H., Yang, Y., Rodriguez, D. A. e Sánchez, B. N. (2020) Neighborhood characteristics and transport walking: Exploring multiple pathways of influence using a structural equation modeling approach. Journal of Transport Geography. 85, 102703. Disponível em: https://doi.org/10.1016/j.jtrangeo.2020.102703

Liao, Y., Shibata, A., Ishii, K., Koohsari, M. J., Inoue, S. e Oka, K. (2018) Can neighborhood design support walking? Cross-sectional and prospective findings from Japan. Journal of Transport e Health. 11, 73-79. Disponível em: https://doi.org/10.1016/j.jth.2018.10.008

Lima, J. P. e Machado, M. H. (2019) Walking accessibility for individuals with reduced mobility: A Brazilian case study. Case Studies on Transport Policy. 7, 269-279. Disponível em: https://doi.org/10.1016/j.cstp.2019.02.007

Linstone, H. A. e Turoff, M. (2002) The Delphi Method: Techniques and Applications. Disponível em:

https://web.njit.edu/ turoff/pubs/delphibook/delphi book.pdf. [Consultado em: 28 de agosto de 2020].

Litman, T. (2021) Evaluating Active Transport Benefits and Costs: Guide to Valuing Walking and Cycling Improvements and Encouragement Programs. Victoria Transport Policy Institute. Disponível em: https://www.vtpi.org/nmt-tdm.pdf. [Consultado em: 25 de abril de 2021].

Liu, Y., Yang, D., Timmermans, H. J. P. e Vries, B. de. (2020) Analysis of the impact of street-scale built environment design near metro stations on pedestrian and cyclist road segment choice: A stated choice experiment. Journal of Transport Geography. 82, 102570. Disponível em: https://doi.org/10.1016/j.jtrangeo.2019.102570

Magnier-Watanabe, R. e Lemaire, J. (2018) Inbound foreign direct investment in Japan: A typol- 
ogy. International Business Review. 27(2), 431442. Disponível em: https://doi.org/10.1016/j.ibusrev.2017.09.010

Makarewicz, C., Adkins, A., Frei, C. e Wennink, A. (2018) "A little bit happy": How performance metrics shortchange pedestrian infrastructure funding. Research in Transportation Business e Management. 29, 144-156. Disponível em: https://doi.org/10.1016/j.rtbm.2019.01.002

Marisamynathan, S. e Lakshmi, S. (2018) Method to determine pedestrian level of service for sidewalks in Indian context. Transportation Letters. 10:5, 294-301. Disponível em: https://doi.org/10.1080/19427867.2016.1264668

Medeiros, V. A. S. de (2006) Urbis Brasiliae ou sobre cidades do Brasil: inserindo assentamentos urbanos do país em investigações configuracionais comparativas. Brasília, 2006. 519 p. Tese (Doutorado). Brasília: UNB - Universidade de Brasília, Faculdade de Arquitetura e Urbanismo, Programa de Pesquisa e Pós-graduação.

Moran, M. R., Rodríguez, D. A., Cotinez-O'Ryan, A., Miranda, J. J. (2020). Park use, perceived park proximity, and neighborhood characteristics: Evidence from 11 cities in Latin America. Cities, 105 , $102817 . \quad$ Disponível em: https://doi.org/10.1016/j.cities.2020.102817

Orellana, D., Bustos, M. E., Marín-Palacios, M., Cabrera-Jara, N. e Hermida, M. A. (2020) Walk'n'roll: Mapping street-level accessibility for different mobility conditions in Cuenca, Ecuador. Journal of Transport e Health. 16, 100821. Disponível

https://doi.org/10.1016/j.jth.2020.100821

Pembuain, A., Priyanto, S. e Suparma, L. B. (2020) The evaluation of tactile ground surface indicator condition and effectiveness on the sidewalk in Yogyakarta City, Indonesia. IATSS Research. 44, 1-7. Disponível em: https://doi.org/10.1016/j.iatssr.2019.04.002

Pitilin, T. R. e Sanches, S. da P. (2020) A caminhabilidade: uma análise bibliométrica. Revista de Morfologia Urbana. 8(2), e00129. Disponível em: https://doi.org/10.47235/rmu.v8i2.129

Ramezani, S., Laatikainen, T., Hasanzadeh, K. e Kyttä, M. (2019) Shopping trip mode choice of older adults: an application of activity space and hybrid choice models in understanding the effects of built environment and personal goals. Transportation. Disponível em: https://doi.org/10.1007/s11116-019-10065-z

Rišová, K. e Madajová, M. S. (2020) Gender differences in a walking environment safety perception: A case study in a small town of Banská Bystrica (Slovakia). Journal of Transport Geography.
85, 102723. Disponível em: https://doi.org/10.1016/j.jtrangeo.2020.102723

Rodriguez-Valencia, A., Barrero, G. A., OrtizRamirez, H. A. e Vallejo-Borda, J. A. (2020) Power of User Perception on Pedestrian Quality of Service. Transportation Research Record: Journal of Transportation Research Board. 2674(5), 250$258 . \quad$ Disponível em: https://doi.org/10.1177/0361198120914611

Rosa, R. (2011) Análise Espacial em Geografia. Revista da ANPEGE. 7(1), 275-289. Disponível em: https://doi.org/10.5418/RA2011.0701.0023

Rother, E. T. (2007) Revisão sistemática X revisão narrativa. Acta Paulista de Enfermagem. 20(2), vvi. Disponível em: https://doi.org/10.1590/S010321002007000200001

Ruiz-Padillo, A., Oliveira, T. B. F. de, Alves, M., Bazzan, A. L. C. e Ruiz, D. P. (2016) Social choice functions: A tool for ranking variables involved in action plans against road noise. Journal of Environmental Management. 178(1), 1-10. Disponível em: https://doi.org/10.1016/j.jenvman.2016.04.038

Ruiz-Padillo, A., Pasqual, F. M., Uriarte, A. M. L. e Cybis, H. B. B. (2018) Application of multicriteria decision analysis methods for assessing walkability: A case study in Porto Alegre, Brazil. Transportation research Part D: Transport and Environment. 63, 855-871. Disponível em: https://doi.org/10.1016/j.trd.2018.07.016

Saraiva, G. J. de P. (2000) Lógica Fuzzy. Revista Militar de Ciência e Tecnologia. XVII(3), 43-66. Disponível em: http://rmct.ime.eb.br/arquivos/revistas/RMCT_3_q uad_2000.pdf. [Consultado em: 08 de setembro de 2020].

Schreuer, N., Plaut, P., Lihi, G. e Dalia, S. (2019) The relations between walkable neighbourhoods and active participation in daily activities of people with disabilities. Journal of Transport e Health. 15, 100630. Disponível em: https://doi.org/10.1016/j.jth.2019.100630

Schulze, M. (2011) A new monotonic, cloneindependent, reversal symmetric, and condorcetconsistent single-winner election method. Social choice and Welfare. 36, 267-303. Disponível em: https://doi.org/10.1007/s00355-010-0475-4

Silva Júnior, L. G., Kikuchi, F. H. N. e Portella, A. (2020) Avaliando o desempenho da caminhada: como a qualidade dos passeios influencia a percepção ambiental do usuário idoso. PIXO - Revista de Arquitetura, Cidade e Contemporaneidade, 4(13), 168-185. DOI: https://doi.org/10.15210/pixo.v13i4.18605 
Speck, J. (2012) Walkable City: how downtown can save America, one step at a time. Nova York, North Point Press.

Spickermann, A., Zimmermann, M. e Von Der Gracht, H. A. (2014) Surface- and deep-level diversity in panel selection - Exploring diversity effects on response behaviour in foresight. Technological Forecasting and Social Change. 85, 105$120 . \quad$ Disponível em: https://doi.org/10.1016/j.techfore.2013.04.009

Su, S., Zhou, H., Xu, M., Ru, H., Wang, W. e Weng, M. (2019) Auditing street walkability and associated social inequalities for planning Implications. Journal of Transport Geography. 74, 62-76. Disponível em: https://doi.org/10.1016/j.jtrangeo.2018.11.003

Trubina, E. (2020) Sidewalk fix, elite maneuvering and improvement sensibilities: The urban improvement campaign in Moscow. Journal of Transport Geography. 83, 102655. Disponível em: https://doi.org/10.1016/j.jtrangeo.2020.102655

Woldeamanuel, M. e Kent, A. (2016) Measuring Walk Access to Transit in Terms of Sidewalk
Availability, Quality, and Connectivity. Journal of Urban Planning and Development. 142(2). Disponível

em: https://doi.org/10.1061/(ASCE)UP.19435444.0000296

Wu, H., Chen, Y. e Jiao, J. (2019) Impact of Neighborhood Built Environments on Shopping Travel Modes in Shanghai, China. Transportation Research Record: Journal of Transportation Research Board. 2673(8), 669-681. Disponível em: https://doi.org/10.1177/0361198119844969

Yang, Y. e McAndrews, C. (2020) Statewide Analysis of Individuals' Exposure to Business Establishments and Active Travel Behavior. Transportation Research Record: Journal of Transportation Research Board. 2674(4), 101-113. Disponível https://doi.org/10.1177/0361198120912241

Yencha, C. (2019) Valuing walkability: New evidence from computer vision methods. Transportation Research Part A. 130, 689-709. Disponível em: https://doi.org/10.1016/j.tra.2019.09.053

\title{
Tradução do título, resumo e palavras-chave
}

Weighted assessment of the perception of sidewalk infrastructure using the Delphi-Fuzzy technique and geospatial analysis

\begin{abstract}
Providing suitable conditions for sidewalk infrastructure is necessary to promote walking in cities. Nevertheless, countless variables may influence the quality of sidewalks from the point of view of the users. Accordingly, this paper presents a method of assessing sidewalks quality by the use of a weighted index based on geospatial analysis and users' perceptions. The quantitative analysis performed involve fuzzy logic and Delphi and Schulze techniques. The method was applied in the central area of a small Brazilian city located in the state of Rio Grande do Sul. The results are discussed based on the selection of important attributes for walking and weighting and perception of these attributes. In general, sensitivity analysis shows that the method is adequate; therefore, it transmit directly the experiences of the urban environment. As a result, this study contributes to the proposition of a method suitable to be used by urban planners to make decisions related to public policies aimed at pedestrian mobility.
\end{abstract}

Keywords: perception, urban infrastructure, GIS, delphi, fuzzy.

Editor responsável pela submissão: Renato Saboya.

Licenciado sob uma licença Creative Commons.

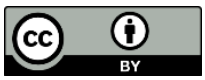

